British Journal of Nutrition (2016), 116, 300-315

doi:10.1017/S0007114516001549

(c) The Authors 2016. This is an Open Access article, distributed under the terms of the Creative Commons Attribution licence (http://creativecommons.org/licenses/by/4.0/), which permits unrestricted re-use, distribution, and reproduction in any medium, provided the original work is properly cited.

\title{
Dietary patterns in the French adult population: a study from the second French national cross-sectional dietary survey (INCA2) (2006-2007)
}

\author{
R. Gazan, C. Béchaux, A. Crépet, V. Sirot, P. Drouillet-Pinard, C. Dubuisson and S. Havard* \\ Risk Assessment Department, French Agency for Food, Environmental and Occupational Health \& Safety (ANSES), 94701 \\ Maisons-Alfort, France
}

(Submitted 20 June 2015 - Final revision received 20 February 2016 - Accepted 21 March 2016 - First published online 18 May 2016)

\section{Abstract}

Identification and characterisation of dietary patterns are needed to define public health policies to promote better food behaviours. The aim of this study was to identify the major dietary patterns in the French adult population and to determine their main demographic, socioeconomic, nutritional and environmental characteristics. Dietary patterns were defined from food consumption data collected in the second French national cross-sectional dietary survey (2006-2007). Non-negative-matrix factorisation method, followed by a cluster analysis, was implemented to derive the dietary patterns. Logistic regressions were then used to determine their main demographic and socio-economic characteristics. Finally, nutritional profiles and contaminant exposure levels of dietary patterns were compared using ANOVA. Seven dietary patterns, with specific food consumption behaviours, were identified: 'Small eater', 'Health conscious', 'Mediterranean', 'Sweet and processed', 'Traditional', 'Snacker' and 'Basic consumer'. For instance, the Health-conscious pattern was characterised by a high consumption of low-fat and light products. Individuals belonging to this pattern were likely to be older and to have a better nutritional profile than the overall population, but were more exposed to many contaminants. Conversely, individuals of Snacker pattern were likely to be younger, consumed more highly processed foods, had a nutrient-poor profile but were exposed to a limited number of food contaminants. The study identified main dietary patterns in the French adult population with distinct food behaviours and specific demographic, socio-economic, nutritional and environmental features. Paradoxically, for better dietary patterns, potential health risks cannot be ruled out. Therefore, this study demonstrated the need to conduct a risk-benefit analysis to define efficient public health policies regarding diet.

Key words: Dietary patterns: Nutritional intakes: Food contaminant exposure: Demographic and socio-economic determinants

Relationships between diet and health have already been strongly established in the literature ${ }^{(1,2)}$. Accordingly, the consumption of some foods (e.g. red meat, fruits, fish, alcohol, etc.) or some nutrients (e.g. SFA, Na, K, etc.) is generally associated with an increased or decreased risk of many chronic diseases such as obesity $^{(3-5)}$, hypertension ${ }^{(6-8)}, \mathrm{CVD}^{(6,9-11)}$ or certain cancers ${ }^{(12-14)}$.

The standard approach for exploring these risk-benefit relationships has been to focus on one specific food or one nutrient without considering the diet as a whole ${ }^{(15)}$. However, it is necessary to consider the potential interactions or synergistic effects between foods or nutrients in order to depict the overall effect of diet on health ${ }^{(15-17)}$. Multidimensional approaches, such as the identification of dietary patterns, thus allow the estimation of more reliable associations between diet and health, taking into account the overall diet and its complexity ${ }^{(18-20)}$. Moreover, the nutritional and socio-economic characterisation of dietary patterns can be used to define practical public health policies to promote better food behaviours in specific groups of consumers ${ }^{(21,22)}$. From an environmental health perspective, dietary patterns can finally contribute to identify the most exposed consumers to a series of food contaminants ${ }^{(23)}$.

In recent years, there has been increasing interest in studying national diets using a multidimensional approach ${ }^{(20,24)}$. The standard approaches applied were principal factor analyses, such as principal component analysis (PCA), multi-component analysis or cluster analysis (e.g. hierarchical cluster analysis $($ HCA $))^{(18,25,26)}$. In France, only a few studies have investigated dietary patterns at a national level using multifactorial methods ${ }^{(27-30)}$, and only one, to our knowledge, from a representative sample of the French population ${ }^{(29)}$. Although these studies have provided comparable results, the lack of homogeneity of the methods performed and differences in the study population make comparisons difficult. Besides, standard approaches are not really suitable for constructing dietary patterns because of the inherent structure of the data. For instance, food consumption data include a significant number of zeros because of non-consumption of certain categories of foods and only have positive values. Hence, the assumption of a Gaussian distribution

Abbreviations: CS, consumption system; DDS, dietary diversity score; ED, energy density; INCA2, Second French National Dietary survey (2006-2007); MAR, mean adequacy ratio; NMF, non-negative matrix factorisation; TEI, total energy intake.

* Corresponding author: S. Havard, email sabrina.havard@anses.fr 
may not be valid ${ }^{(31)}$. Moreover, the approaches usually used show poor fit because of non-negative data and the excess of zero values, generally termed 'sparse data' ${ }^{\text {(32) }}$. Lee \& Seung ${ }^{(33)}$ proposed a new latent-variable-based method, the negative matrix factorisation (NMF) method, specifically adapted to sparse and non-negative data. This method has already been proven to be effective in food risk assessment to identify dietary patterns or chemical mixtures ${ }^{(23,34,35)}$.

The major aim of this study was thus to identify the main dietary patterns in the French adult population using the NMF approach and the food consumption data of a nationally representative survey (the second French national cross-sectional dietary survey (INCA2)). Next, we determined their main demographic and socio-economic characteristics and assessed their nutritional and environmental profiles in order to highlight their specific features. The dietary patterns revealed in this work will thus give an overview of the different food consumption behaviours in the French adult population, according to distinct dimensions.

\section{Methods}

\section{Study population}

The French INCA2 survey was carried out between December 2005 and May 2007 by the French Food Safety Agency ${ }^{(36)}$. This cross-sectional survey was initially designed to assess food intake in a nationally representative sample of the French population. Two independent random samples of 3- to 17-year-old children and 18- to 79-year-old adults were drawn using a multistage cluster sampling technique. The complex sampling frame was established from the national census, published by the French National Institute of Statistics and Economic Studies (INSEE), and it has been described elsewhere ${ }^{(37,38)}$. In brief, 181 geographical units, stratified by region of residence and size of urban area, were first randomly selected with a probability proportional to size. Then, households were randomly drawn within each primary sampling unit, and two independent sampling frames were set up: one restricted to households including at least one child and the other including households with or without children. Last, within each household, either a child or an adult was randomly selected. Participation rates were $63 \%$ for adults and $69 \%$ for children, yielding samples of 2624 adults and 1455 children, respectively. To ensure the national representativeness of each sample, a weighting factor for unequal sampling probabilities for differential non-responses by region, agglomeration size, age, sex, occupation of the household head, size of the household and season has been assigned to each individual. These variables were selected for adjustment because of high discrepancy between their distribution among the INCA2 sample and among the French population, using an external source (Labour force survey 2005-INSEE) ${ }^{(36,39)}$ (distribution among the adult sample is presented in the online Supplementary Table S1). The low variability of the weighting factor for adults (mean of 1 and a SD of 0.7 ) demonstrated the good representativeness of the INCA2 adult sample compared with the French general adult population.

Only adults were considered in this study. As recommended by the European Food Safety Authority, under-reporting subjects (i.e. those who, voluntarily or not, under-reported amounts consumed; $26.9 \%$ of adult sample) were identified and included in the statistical analyses ${ }^{(40)}$. Besides, twentyfour subjects $(0.9 \%$ of the adult sample) with an extremely low total energy intake (TEI) were excluded from the final sample (estimated from the following formula: $\log ($ TEI $)<\operatorname{mean}(\log (\text { TEI })-3 \operatorname{sD}(\log (\text { TEI })))^{(41)}$

The INCA2 survey was approved by the French Data Protection Authority (Commission Nationale de l'Informatique et des Libertés) and the French National Council for Statistical Information (Conseil National de l'Information Statistique).

\section{Data}

Collection of data on food consumption. Dietary intake was assessed using a 7-d food record. A trained and certified investigator delivered at home the food record with a selfadministered questionnaire and explained to the subjects how to complete them. The investigator returned to the home immediately after the week to check the accuracy of the information reported in both documents. Each day of the food record was divided into three main meals (breakfast, lunch and dinner) and three between-meal snacks. The subjects were asked to describe as precisely as possible the nature and the amount of all foods and beverages consumed during the survey week. Consumed quantities were estimated using the SU.VI.MAX (SUpplémentation en VItamines et en MInéraux AntioXydants) photographic booklet ${ }^{(42)}$ or expressed directly in weight or in household measures (e.g. spoon).

Foods and beverages declared were subsequently allocated a food code including 1280 food items and were categorised into forty-three food groups and 121 subgroups. McCann et al. ${ }^{(43)}$ and preliminary analyses (data not shown) showed that the quality of the description of dietary patterns is strongly affected by the level of aggregation of foods. To obtain a satisfactory trade-off between the level of detail to discriminate individuals according to their food consumption and the difficulty in exploring a large data set by factorial analysis, the nomenclature was modified step-by-step for this study and the 1280 food items were finally reclassified into seventy-four new food groups (Table 1). This classification was based on the foods' nutritional composition and results of previous analyses (data not shown). Eight food groups (i.e. wholegrain pasta/rice/ wheat, whole milk, skimmed milk, sweetened milk, low-fat cheese, dried fruit, nectar, soft drinks with fruit) with a consumption rate $<10 \%$ were excluded to avoid excessive noise in the data, which could lead to underline too particular and isolated dietary behaviours ${ }^{(44,45)}$.

\section{Individual characteristics}

Individual demographic and socio-economic variables were collected using face-to-face questionnaires and self-reported data. Questionnaires provided information on individual occupational status, education level and household wealth. Household wealth was defined through questions on the household income and other related variables such as having gone away on holiday for more than $4 \mathrm{~d}$ within the last 12 months', 'the number of cars in the household', 'the number 
Table 1. Nomenclature

(food groups and consumption rate among the 2600 individuals)

\begin{tabular}{|c|c|c|c|c|c|}
\hline Food groups & $\begin{array}{l}\text { Consumption } \\
\text { rate }(\%)\end{array}$ & Food groups & $\begin{array}{l}\text { Consumption } \\
\text { rate }(\%)\end{array}$ & Food groups & $\begin{array}{l}\text { Consumption } \\
\text { rate }(\%)\end{array}$ \\
\hline Bread product with wheat flour & 94.0 & Red meat & $90 \cdot 2$ & Soft drinks with fruit & 4.0 \\
\hline $\begin{array}{l}\text { Bread product with multigrain or } \\
\text { wholemeal flour }\end{array}$ & 34.7 & Poultry & $70 \cdot 7$ & Sodas and colas & $32 \cdot 2$ \\
\hline Breakfast cereal & $17 \cdot 0$ & Offal & $15 \cdot 1$ & Other soft drinks & $21 \cdot 1$ \\
\hline Refined pasta, rice, wheat & $90 \cdot 7$ & Other meat & $17 \cdot 7$ & Alcoholic drinks & $67 \cdot 7$ \\
\hline Wholegrain pasta, rice, wheat & $2 \cdot 9$ & Processed meat & $17 \cdot 7$ & Coffee & $21 \cdot 3$ \\
\hline Puff pastries & $46 \cdot 2$ & Unprocessed fish & $70 \cdot 8$ & Chicory coffee & $10 \cdot 3$ \\
\hline $\begin{array}{l}\text { Sweetened biscuits and cereal } \\
\text { bars }\end{array}$ & 38.0 & Processed fish products & $16 \cdot 0$ & Tea, herbal tea and infusions & $38 \cdot 2$ \\
\hline Crackers & $28 \cdot 3$ & Crustaceans and molluscs & 31.7 & Pizza & $35 \cdot 6$ \\
\hline Cakes and pastries & $67 \cdot 1$ & Vegetables & $98 \cdot 7$ & Quiches & $22 \cdot 9$ \\
\hline Donut pancake waffle & $16 \cdot 1$ & $\begin{array}{l}\text { Potatoes and other } \\
\text { unprocessed tubers }\end{array}$ & $50 \cdot 1$ & $\begin{array}{l}\text { Savoury pastries not fried, not } \\
\text { breaded }\end{array}$ & $11 \cdot 2$ \\
\hline Whole milk & 4.0 & Processed potato products & $77 \cdot 1$ & $\begin{array}{l}\text { Savoury pancakes, blinis, } \\
\text { quenelles }\end{array}$ & $12 \cdot 2$ \\
\hline Semi-skimmed milk & 43.0 & Pulses & 29.5 & $\begin{array}{l}\text { Processed fried or breaded } \\
\text { product }\end{array}$ & $29 \cdot 6$ \\
\hline Skimmed milk & $5 \cdot 2$ & Fruits & 84.5 & Sandwiches & 38.9 \\
\hline Sweetened milk & 7.9 & Dried fruits & $9 \cdot 8$ & Soup and stock & $49 \cdot 4$ \\
\hline Regular-fat cream & 24.7 & Grains and nuts & 20.5 & Mixed dishes with meat & 38.6 \\
\hline Yogurt and cottage cheese $0 \%$ fat & $74 \cdot 3$ & Ice cream and sherbet & $30 \cdot 7$ & Cereal-based mixed dishes & 32.9 \\
\hline Yogurt and cottage cheese $20 \%$ fat & $54 \cdot 1$ & $\begin{array}{l}\text { Chocolate and chocolate } \\
\text { confectionery }\end{array}$ & $49 \cdot 6$ & Mixed dishes with vegetables & $14 \cdot 1$ \\
\hline $\begin{array}{l}\text { Yogurt and cottage cheese } \\
30-40 \% \text { fat }\end{array}$ & $55 \cdot 9$ & $\begin{array}{l}\text { Sugar and derivatives } \\
\text { (not substitutes) }\end{array}$ & $66 \cdot 1$ & Mixed salad & $22 \cdot 3$ \\
\hline Regular-fat cheese (not low-fat) & 88.7 & Non-chocolate confectionery & $13 \cdot 1$ & Dairy dessert & $52 \cdot 3$ \\
\hline Low-fat cheese & $8 \cdot 3$ & $\begin{array}{l}\text { Regular honey and jam } \\
\text { (not reduced sugar) }\end{array}$ & $45 \cdot 2$ & Processed fruit & $30 \cdot 7$ \\
\hline Eggs & $61 \cdot 2$ & $\begin{array}{l}\text { Reduced-sugar jam and } \\
\text { confectionery }\end{array}$ & $12 \cdot 9$ & Hot sauces & $54 \cdot 4$ \\
\hline Butter and other animal fat & $73 \cdot 3$ & Bottled water & $70 \cdot 3$ & $\begin{array}{l}\text { Condiment and cold dip, reduced } \\
\text { fat }\end{array}$ & $11 \cdot 8$ \\
\hline Oil & 81.4 & Tap water & $66 \cdot 4$ & $\begin{array}{l}\text { Regular fat condiment and cold dip } \\
\text { (not low-fat) }\end{array}$ & $79 \cdot 6$ \\
\hline Margarine and other vegetable fat & 19.5 & Fruit juice & 51.5 & Herbs and spices & $41 \cdot 0$ \\
\hline Low-fat spread (vegetal or animal) & $45 \cdot 7$ & Nectar & $2 \cdot 4$ & & \\
\hline
\end{tabular}

of domestic electrical appliances', 'how the financial situation is perceived', 'financial access to desired food products', 'whether the idea of lacking food would be a concern', 'giving up health care for financial reasons' and 'housing occupancy status'. A wealth index was derived from a correspondence analysis as already done by Fillol et $a l^{(46)}$ on variables describing household wealth (cited above). From the correspondence analysis, the score of each subject on the first principal component was used as the summary wealth index, which was divided into tertiles. In addition, for this study and according to Darmon et al. ${ }^{(47)}$, an individual was considered as living in a household experiencing food insecurity for financial reasons if she/he declared not having enough to eat (often or sometimes) because of economic reasons. Respondents were also asked to report other information such as age, sex, household composition, region and size of municipality in which the household was located. The variables and associated categories are described in the supporting information (online Supplementary Table S2).

Nutritional composition data. Nutritional intake was estimated by matching the French Food Composition database for the year $2008^{(48,49)}$ to the individual food consumption data. The individual average daily intake of macronutrients (i.e. total energy content, total carbohydrates, simple carbohydrates, total fats, SFA, proteins, alcohol, fibres and salt), minerals (i.e. Ca, Fe, $\mathrm{Na}, \mathrm{Mg}, \mathrm{K}$ ) and vitamins (i.e. vitamins $\mathrm{A}, \mathrm{C}, \mathrm{E}, \mathrm{B}_{1}, \mathrm{~B}_{6}, \mathrm{~B}_{9}$ ) was thus determined.

Food contamination data. Food contamination data were provided by the Second French Total Diet Study (TDS2). The TDS2 was conducted between 2006 and 2010 to evaluate the exposure of the French population to various substances that are likely to be found in foods 'as consumed'. This study collected 20000 food products, representing 212 types of food, for which 445 substances of interest were investigated. Food sampling was based on the data from the INCA2 survey, covering about $90 \%$ of dietary consumption in the adult and child populations ${ }^{(50)}$. The 212 foods selected were linked to the INCA2 nomenclature. Of the 445 substances analysed, ten chemical substances, for which toxicological risk could not be excluded, were considered in this study ${ }^{(50)}$ : trace elements (i.e. $\mathrm{Pb}, \mathrm{Al}, \mathrm{Cd}$, inorganic $\mathrm{As}$, organic $\mathrm{Hg}$ ), acrylamide, one mycotoxin (i.e. deoxynivalenol (DON) and its acetylated 
derivatives), polychlorinated biphenyls (PCB)/dioxins (i.e. non-dioxin-like polychlorinated biphenyls (NDL-PCB), polychlorinated dibenzo- $p$-dioxins and dibenzofurans and dioxinlike polychlorinated biphenyl) and one additive (sulphites). The individual average daily exposure levels to the ten substances were estimated by combining individual food consumption data and contamination data from the food sample analysis, considering the same hypotheses as those described in the TDS2 report ${ }^{(51,52)}$.

\section{Statistical analyses}

Identification of dietary patterns. The NMF method was applied to the data set composed of the 2600 individual daily intake $(\mathrm{g} / \mathrm{d})$ of the sixty-six food groups. The analysis was performed on the overall adult population because similar dietary patterns were identified separately in men and women (data not shown). To account for individual weight in pattern identification, the iterative least squares (LS)-NMF algorithm developed by Wang et al. ${ }^{(53)}$ and based on that described by Lee \& Seung ${ }^{(33)}$ was used. The goal of this factorial analysis is to summarise the information available in food consumption data into an optimal number $k$ of consumption systems $(\mathrm{CS})^{(23,34,35)}$. In contrast to the PCA technique, each $C S_{k}$ in the NMF is defined as a positive linear combination of foods, which are generally associated in the same diet. Thus, all $C S_{k}$ describe the different associations of foods within the population. For each $C S_{k}$, each food group had a coefficient that can be interpreted as the contribution of this food group to the construction of the system $C S_{k}$. The weight of each $C S_{k}$ in each individual's total diet was also determined. The diet of an individual is thus represented by a combination of different $C S_{k}$.

To implement the NMF method, an optimal number of CS must be chosen. In this study, it was selected according to the quality of the interpretation of the CS (relevancy and ease of interpretation) and a graphical approach as done in Béchaux et $a l^{(23)}$ and Sy et $a l^{(35)}$. Finally, a HCA was conducted to identify individuals with similar combinations of CS, defining a dietary pattern. The scores of each individual on the CS selected were used as input to the HCA. This classical clustering method consists of a step-by-step aggregation of individuals or groups of individuals who combined the CS in a similar way ${ }^{(54)}$, leading to one single class that includes the entire population. The number of clusters to retain was based on the inter-cluster inertia:total inertia ratio and the interpretability of the different clusters.

For each dietary pattern, the relative contribution (\%) of each $C S_{k}$ was calculated (i.e. among individuals within the same dietary pattern, the contribution of the $C S_{k}$ is the ratio between the sum of weights of the $C S_{k}$ and the sum of the weights of all the CS). The CS that best describes each pattern was identified according to the $\mathrm{V}$ test indicator, which compares the average weight of the $C S_{k}$ in one dietary pattern with the average weight of the $C S_{k}$ in the whole population ${ }^{(55,56)}$. The $C S_{k}$ with significant and positive $\mathrm{V}$ tests were used to describe dietary patterns.

Characterisation of the dietary patterns. Demographic and socio-economic characteristics of each dietary pattern were investigated using binomial logistic regression. Each tested model identified the main demographic and socio-economic determinants of each dietary pattern independently of the others, by comparing with the overall population. Variables considered were age, level of education, wealth index, household size, household composition, occupational status, region, food insecurity and municipality size. These factors were selected because of their significant associations with the dietary patterns in univariate analysis (data not shown), as well as the consistent associations between dietary intake and these demographic and socio-economic determinants ${ }^{(57-61)}$. All analyses were performed among men and women separately in order to take into account the significant interaction observed between sex and other factors (data not shown).

The mean nutrient intake was calculated for each dietary pattern. The association between nutritional intake and dietary patterns was assessed using ANOVA, and specific nutrient intake was identified by comparing the mean of each dietary pattern with the overall mean. All models were controlled for age, sex, season, TEI, level of education, wealth index, occupational status, household size, food insecurity, household composition, municipality size and region. As previously mentioned, these covariates were selected on preliminary analyses and previous studies ${ }^{(57-61)}$.

Diet quality indices can evaluate the overall diet of an individual based on the following: (i) nutrient indicators, which reflect the adequacy to nutritional requirements; and (ii) foods to assess the variety of food intake ${ }^{(62,63)}$. Three scores were selected to illustrate the overall quality of the diet: the energy density (ED) of the diet ${ }^{(64)}$, the mean adequacy ratio (MAR) ${ }^{(65)}$ and the dietary diversity score (DDS) ${ }^{(66)}$. The ED was used as an indicator of bad nutritional quality. Low ED has been shown to have a good nutritional quality ${ }^{(67)}$, and a decrease of ED of the diet is recommended by several public health authorities to prevent obesity ${ }^{(68,69)}$. For this study, ED was calculated for each individual with respect to the energy content $(\mathrm{kJ} / \mathrm{g}(\mathrm{kcal} / \mathrm{g}))$ of all foods consumed (except beverages such as water, soft drinks, alcohol, milk, coffee, tea). The mean ED was assessed for each dietary pattern. MAR was used as an indicator of good nutritional quality. The MAR represents the nutritional adequacy of the diet. Multiple versions of this index have been related to health indicators ${ }^{(70)}$, as well to other diet quality indexes ${ }^{(71-73)}$. It was calculated as the mean percentage of the French daily recommended intake for twenty keys nutrients (namely proteins, fibres, vitamins A, C, E, D, B $1, \mathrm{~B}_{2}, \mathrm{~B}_{3}, \mathrm{~B}_{6}, \mathrm{~B}_{9}, \mathrm{~B}_{12}$, Ca, K, $\mathrm{Fe}, \mathrm{Mg}, \mathrm{Zn}, \mathrm{Cu}, \mathrm{I}$ and $\mathrm{Se}$ ). Each ratio was truncated at 100, so that a high intake of one nutrient could not compensate for the low intake of another: $M A R_{i}=\frac{1}{20} \times \sum_{n}^{n} 20 \frac{\text { intake }_{i, n}}{R D A_{n}} \times 100$ where intake $_{i, n}$ is the individual nutrient intake of the nutrient $n$ and $R D A_{n}$ is the French RDA for the nutrient, taking into account the age and the sex of the individual ${ }^{(65)}$. Besides, the diet diversity is also a key element of the high quality of diets. A diverse diet increased the probability of nutrient adequacy ${ }^{(74)}$, and it has been associated with positive health outcomes ${ }^{(75,76)}$. DDS is defined as the number of specific food groups consumed over a specific period $^{(66,77)}$. In this study, $3 \mathrm{~d}$ were randomly chosen for each subject: 2 weekdays and 1 weekend day. Five food groups were considered: dairy products (milk, yogurt, cheese), 
meat (red meat, poultry, fish and crustaceans), cereals (rice, pasta, wheat), fruits (fresh fruit, processed fruit and dry fruit) and vegetables (fresh vegetables and prepared vegetables). A food group was considered to have been consumed if at least $30 \mathrm{~g}$ was ingested during the $3 \mathrm{~d}$. A DDS score was calculated for each individual, and it varied from 0 to 5 . The mean DDS score was calculated for each pattern. Associations between dietary patterns and diet quality scores were also assessed using ANOVA adjusted for covariates, as described above. The mean of quality scores of each dietary pattern was thus compared with the overall mean.

Finally, mean contaminant exposure levels were calculated for each dietary pattern. Associations between dietary patterns and exposure levels were assessed using ANOVA-adjusted covariates described above. On the basis of the ANOVA model, specific exposure levels were identified by comparing the mean contaminant levels of each dietary pattern with the overall mean.

All values were survey-weighted means. A $P$ value of 0.05 was used as the threshold of significance. All analyses were implemented in the software $\mathrm{R}$ version 3.0.2. The LS-NMF algorithm was implemented using the R package ' $\mathrm{NMF}{ }^{\text {(78) }}$. The package 'Factominer' was used to run the clustering ${ }^{(55)}$. The package 'Survey' was used to account for the complex INCA2 sampling frame design ${ }^{(79)}$.

\section{Results}

\section{Identification of dietary patterns}

By combining graphical and interpretability criteria, seven distinct CS summarised the consumption behaviours of the 2600 individuals with respect to the sixty-six food groups. The inclusion of additional CS did not provide any further useful information for the interpretation of the dietary patterns. Moreover, additional CS were difficult to interpret, as they were composed of very few food groups (data not shown). Food groups with a score $\geq 2.5 \%$ were considered as main contributors to a CS. Table 2 shows the relative contribution of the main food groups associated with each of the seven CS, designated as 'Tradition', 'Snacking', 'Mediterranean', 'Simplicity', 'Dietetic', 'High-fat/sugar/salt' and 'Pleasantand-convenient' food behaviours. No strong Pearson's correlations $(<0 \cdot 2715)$ were found between the different CS, suggesting that food behaviours related to each CS were independent of each other.

Then, seven dietary patterns with homogeneous CS combinations were identified and named according to their food consumption patterns. The major CS that best described each dietary pattern were identified and presented in Table 2. In brief, the first dietary pattern called 'Small eater' represented $23.0 \%$ of the population. It consisted of consumers who used all the CS but to a lesser extent than the overall population, which means that they consumed all foods but in a lower quantity than the overall population. The second dietary pattern called 'Health conscious' grouped $12.6 \%$ of the population and was characterised by individuals who used the dietetic CS significantly more than the overall population, which was mainly associated with low-fat or light foods, soups, fruits, tea and herbal tea and, paradoxically, cakes and pastries. The third dietary pattern, named 'Mediterranean', grouped $13.0 \%$ of the population and was represented by individuals who used the Mediterranean CS significantly more than the overall population, which was characterised by unprocessed foods (vegetables, oil, herbs and spices, unprocessed fish, unprocessed fruit, etc.) and dairy products (condiments and cold dips (not low-fat), yogurt and cottage cheese (30-40\% fat)). Individuals in the fourth dietary pattern called 'Sweet and processed' grouped $13.5 \%$ of the population. This pattern was characterised by food behaviour represented by the Pleasantand-convenient CS characterised by an association of sweetened products such as breakfast cereals, fruit juices, chocolate bars/confectionery, dairy desserts and meals easy to prepare such as puff pastries, quiches, warm sauces, cereal-based mixed dishes, etc. The fifth dietary pattern identified as 'Traditional' accounted for $16.5 \%$ of the population and was represented by individuals who followed the Tradition CS significantly more than the overall population and the High-fat/sugar/salt CS. Individuals in this pattern were therefore characterised by a consumption of foods such as alcohol (in particular wine), processed meat, cheese, bread products with wheat flour, coffee, red meat, but also crackers, confectionery without chocolate, grains and nuts, cakes and pastries, and sweetened biscuits, which characterised the High-fat/sugar/salt CS. The sixth pattern, identified as 'Snacker', was represented by $11.5 \%$ of the population and was characterised by individuals who followed the Snacking CS, mainly represented by take-away products such as sandwiches, pizza, sodas and colas, puff pastries (such as ham puff pastry, 'bouchée à la reine', etc.) and processed foods such as processed potato products and cerealbased mixed dishes (as spaghetti carbonara, pasta gratin, etc.). This pattern also followed the High-fat/sugar/salt CS more than the overall population. The last dietary pattern called 'Basic consumer' accounted for $10.0 \%$ of the population and was characterised by individuals who followed the Simplicity CS, which associated mostly simple foods such as butter/other animal fat, refined pasta/rice/wheat, unprocessed potatoes, yogurt and cottage cheese (20\% fat), bread and bread products (including bread, loaf and rusk).

\section{Characterisation of dietary patterns}

OR and $95 \%$ from logistic regressions are detailed in the Table 3 for men and women separately. Regardless of sex, the probability of belonging to the Health-conscious and Mediterranean dietary patterns (only for men in Traditional pattern) increased with age, conversely to the probability of belonging to the Sweet-and-processed and Snacker dietary patterns. In addition, both women and men in the Healthconscious pattern were more likely to have a higher wealth index, as well as women from the Mediterranean pattern. In contrast, men in the Snacker pattern were more likely to have a relatively low wealth index. Women from the Traditional and Small-eater patterns were more likely to have a low educational level conversely to women from the Mediterranean pattern. Women belonging to the Traditional, Snacker or 
Table 2. Food consumption characteristics of each dietary pattern

\begin{tabular}{|c|c|c|c|c|c|c|}
\hline Dietary patterns & Major $\mathrm{CS}^{*}$ & $\%{ }^{*}$ & Major food $\dagger$ & $\% \dagger$ & Major food $†$ & $\% †$ \\
\hline $\begin{array}{l}\text { Small eater } \\
(23.0 \%) \ddagger\end{array}$ & $\begin{array}{l}\text { All CS contributed less than in the } \\
\text { overall population }\end{array}$ & - & - & - & - & - \\
\hline \multirow[t]{8}{*}{$\begin{array}{l}\text { Health conscious } \\
\qquad(12 \cdot 6 \%) \ddagger\end{array}$} & Dietetic & $42 \cdot 7$ & $\begin{array}{l}\text { Bread and bread products with multigrain or } \\
\text { wholemeal flour }\end{array}$ & $7 \cdot 1$ & Vegetables & $4 \cdot 1$ \\
\hline & & & Low-fat spread (vegetable or animal) & $7 \cdot 1$ & Low-fat condiment and dip & 3.9 \\
\hline & & & Bottled water & $6 \cdot 6$ & $\begin{array}{l}\text { Reduced-sugar jam and } \\
\text { confectionery }\end{array}$ & $3 \cdot 8$ \\
\hline & & & Soup and stock & $6 \cdot 3$ & Cakes and pastries & $3 \cdot 8$ \\
\hline & & & Processed fruit & $6 \cdot 0$ & Tea and herbal tea & 3.4 \\
\hline & & & Fruit & $5 \cdot 7$ & Crustaceans and molluscs & $3 \cdot 1$ \\
\hline & & & Yogurt and cottage cheese ( $0 \%$ fat $)$ & $5 \cdot 0$ & Regular honey and jam & 2.9 \\
\hline & & & Unprocessed fish & $4 \cdot 7$ & Coffee & 2.5 \\
\hline \multirow{8}{*}{$\begin{array}{l}\text { Mediterranean } \\
\quad(13.0 \%) \ddagger\end{array}$} & Mediterranean & $37 \cdot 2$ & Vegetables & $12 \cdot 7$ & Eggs & 3.9 \\
\hline & & & Oil & $11 \cdot 2$ & $\begin{array}{l}\text { Yogurt and cottage cheese } \\
\text { (30-40\% fat) }\end{array}$ & $3 \cdot 6$ \\
\hline & & & Regular fat (not low-fat) condiment and dips & $9 \cdot 8$ & Tea and herbal teas & 3.6 \\
\hline & & & Herbs and spices & $7 \cdot 0$ & $\begin{array}{l}\text { Regular honey and jam (not } \\
\text { reduced sugar) }\end{array}$ & $2 \cdot 5$ \\
\hline & & & Tap water & $6 \cdot 6$ & & \\
\hline & & & Unprocessed fish & $6 \cdot 4$ & & \\
\hline & & & Fruit & $6 \cdot 3$ & & \\
\hline & & & Poultry & $4 \cdot 7$ & & \\
\hline \multirow{9}{*}{$\begin{array}{l}\text { Sweet and } \\
\text { processed } \\
(13.5 \%) \ddagger\end{array}$} & Pleasant and convenient & $39 \cdot 7$ & Semi-skimmed milk & $9 \cdot 1$ & Quiches & 3.5 \\
\hline & & & Fruit juice & $6 \cdot 5$ & Processed potato products & 3.5 \\
\hline & & & Breakfast cereal & $6 \cdot 3$ & Bottled water & 3.4 \\
\hline & & & Chocolate and chocolate confectionery & $5 \cdot 2$ & Cereal-based mixed dishes & $3 \cdot 2$ \\
\hline & & & Puff pastries & 4.9 & Sweet biscuits and cereal bars & 2.9 \\
\hline & & & Yogurt and cottage cheese (30-40\% fat) & 4.9 & Processed meat & $2 \cdot 7$ \\
\hline & & & Dairy desserts & $4 \cdot 6$ & $\begin{array}{l}\text { Savoury pastries (not fried, not } \\
\text { breaded) }\end{array}$ & $2 \cdot 5$ \\
\hline & & & Ice cream and sherbet & 4.5 & & \\
\hline & & & Hot sauce & $4 \cdot 3$ & & \\
\hline \multirow{17}{*}{$\begin{array}{l}\text { Traditional } \\
\qquad(16.5 \%) \ddagger\end{array}$} & Traditional & 44.5 & Processed meat & $9 \cdot 5$ & Offal & $3 \cdot 1$ \\
\hline & & & Alcoholic drinks & 9 & Vegetables & 3.0 \\
\hline & & & Regular-fat cheese & $7 \cdot 9$ & Mixed dishes with meat & 2.9 \\
\hline & & & Red meat & $7 \cdot 0$ & Poultry & 2.7 \\
\hline & & & Wheat bread or bread product & $6 \cdot 6$ & & \\
\hline & & & Coffee & $6 \cdot 0$ & & \\
\hline & & & Processed potato products & $4 \cdot 6$ & & \\
\hline & High fat/sugar/salt & $7 \cdot 1$ & Sugar and derivatives (not substitutes) & $3 \cdot 6$ & & \\
\hline & & & Crackers & $16 \cdot 1$ & $\begin{array}{l}\text { Sugar and derivatives (not } \\
\text { substitutes) }\end{array}$ & $3 \cdot 1$ \\
\hline & & & Confectionery without chocolate, not diet & $9 \cdot 8$ & Refined pasta and rice & $3 \cdot 0$ \\
\hline & & & Grains and nuts & $9 \cdot 5$ & Regular-fat cheese & 2.9 \\
\hline & & & Other soft drinks & $8 \cdot 4$ & Dairy dessert & $2 \cdot 8$ \\
\hline & & & Ice cream and sherbet & $4 \cdot 1$ & Sweet biscuits and cereal bars & 2.6 \\
\hline & & & Savoury pancakes, blinis and quenelles & $4 \cdot 0$ & Coffee & $2 \cdot 5$ \\
\hline & & & Processed products, fried or breaded & 3.9 & & \\
\hline & & & Processed fish products & $3 \cdot 3$ & & \\
\hline & & & Cakes and pastries & $3 \cdot 1$ & & \\
\hline \multirow[t]{9}{*}{ Snacker $(11.5 \%) \ddagger$} & Snacking & $38 \cdot 4$ & Sandwiches & $12 \cdot 6$ & Puff pastries & $4 \cdot 1$ \\
\hline & & & Pizza & $12 \cdot 3$ & $\begin{array}{l}\text { Processed product, fried or } \\
\text { breaded }\end{array}$ & $3 \cdot 8$ \\
\hline & & & Sodas and colas & $11 \cdot 3$ & $\begin{array}{l}\text { Chocolate and non-chocolate } \\
\text { confectionery }\end{array}$ & 3.6 \\
\hline & & & Refined pasta and rice & $6 \cdot 8$ & Mixed dishes with meat & $2 \cdot 8$ \\
\hline & & & Processed potato products & $5 \cdot 9$ & & \\
\hline & & & Cereal-based mixed dishes & $5 \cdot 3$ & & \\
\hline & & & Poultry & $5 \cdot 2$ & & \\
\hline & & & Red meat & $4 \cdot 6$ & & \\
\hline & High fat/sugar/salt & $14 \cdot 2$ & See Traditional dietary pattern & & & \\
\hline \multirow[t]{8}{*}{$\begin{array}{l}\text { Basic consumer } \\
\quad(10.0 \%) \ddagger\end{array}$} & Simplicity & $40 \cdot 8$ & Regular-fat butter and other animal fats & $10 \cdot 0$ & $\begin{array}{l}\text { Honey and regular jam (not } \\
\text { reduced sugar) }\end{array}$ & 3.5 \\
\hline & & & Refined pasta and rice & $8 \cdot 3$ & Soup and stock & 3.4 \\
\hline & & & Unprocessed potatoes & $7 \cdot 0$ & Regular-fat fresh cream & $3 \cdot 3$ \\
\hline & & & Yogurt and cottage cheese $(20 \%)$ & $7 \cdot 0$ & $\begin{array}{l}\text { Sugar and derivatives (not } \\
\text { substitutes) }\end{array}$ & $3 \cdot 2$ \\
\hline & & & Wheat bread and bread products & $6 \cdot 3$ & $\begin{array}{l}\text { Processed product, fried or } \\
\text { breaded }\end{array}$ & $2 \cdot 8$ \\
\hline & & & Red meat & $5 \cdot 6$ & Donuts, pancakes and waffles & 2.5 \\
\hline & & & Eggs & $5 \cdot 5$ & Fruit & 2.5 \\
\hline & & & Pulses & $4 \cdot 0$ & & \\
\hline
\end{tabular}


Table 2. Continued

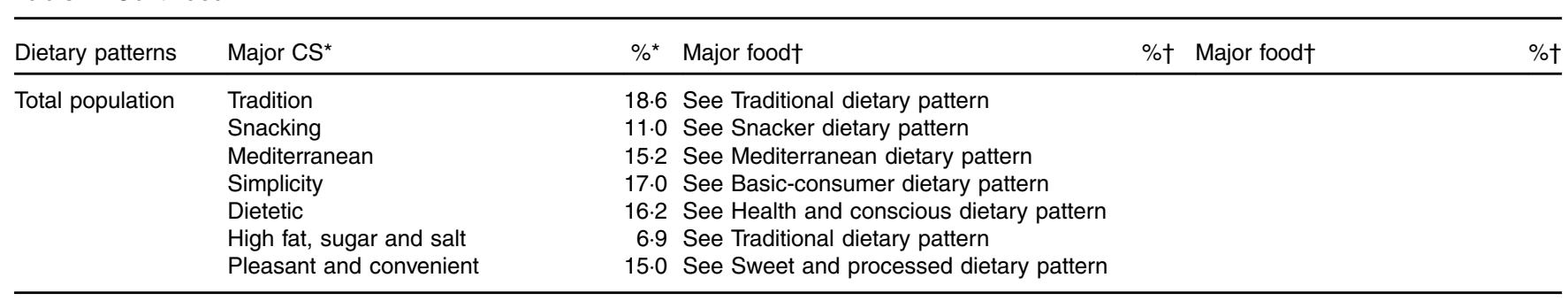

CS, consumption system.

* CS contributing significantly more than the overall population (name and \% of contribution).

† Foods contributing $>2.5 \%$ to the construction of the CS (name and $\%$ of contribution).

$\ddagger$ Individuals in the population (\%).

Health-conscious dietary patterns were more likely to live in households experiencing food insecurity, compared with women from the Small-eater, Mediterranean and Sweetand-processed dietary patterns. Among men, individuals from the Sweet-and-processed dietary pattern were more likely to live in households experiencing food insecurity, conversely to men belonging to the Traditional and Small-eater dietary patterns. The Mediterranean and Snacker dietary patterns had a higher probability of living in large towns or cities.

Nutritional intake for each dietary pattern is shown in Table 4. The energy intake was lower than the overall population for the Small-eater but higher for the Sweet-and-processed, Traditional and Basic-consumer dietary patterns. These three latter dietary patterns were also characterised by higher intake of SFA, mainly because of a higher consumption of savoury or sweet pastries, chocolate for Sweet-and-processed pattern and higher consumption of animal products (i.e. butter, cream, cheese or red meat) for Traditional and Basic-consumer patterns. The Health-conscious and Mediterranean dietary patterns had higher intake of fibres than the overall population, primarily because of a higher consumption of fruits, vegetables and wholemeal bread (for Health-conscious pattern only), leading also to higher intake of many minerals and vitamins than the overall population. In addition, Sweet-and-processed pattern showed higher intake of some minerals and vitamins, probably because of a higher consumption of fruits juice and breakfast cereals (which are, for most of them, fortified). Conversely, the Small-eater, Snacker, Traditional and Basicconsumer dietary patterns showed intake of almost all mineral and vitamins studied, which was lower than the overall population. Only the Traditional and Health-conscious dietary patterns had higher intake of $\mathrm{Na}$ than the overall population, primarily because of a high consumption of cheese and processed meat and a high consumption of wholemeal bread and bottled water for each pattern, respectively.

Scores of nutritional quality (DDS, MAR, ED) were significantly different across dietary patterns (Table 4). Mostly because of an insufficient intake of fruits and vegetables, the Traditional and Snacker dietary patterns showed significantly lower DDS values than the overall population; 20.4 and $30.7 \%$ of individuals from the Traditional and Snacker dietary patterns, respectively, had a DDS value of 4 , and 13.5 and $6.3 \%$, respectively, had a DDS value of 3 (data not shown). Conversely, the Health-conscious and Mediterranean dietary patterns consumed at least $30 \mathrm{~g}$ of dairy products, meat, cereals, fruits and vegetables over $3 \mathrm{~d}$, leading to higher DDS values than the overal population; 95 and $92 \%$ of consumers, respectively, had a DDS value of 5 (data not shown). The MAR, a composite indicator for nutrient adequacy, was higher than the mean in the overall population for individuals from the Health-conscious and Mediterranean dietary patterns, as well as for Sweet-and-processed and Basic-consumer dietary patterns. Individuals from the Health-conscious and Mediterranean patterns, who consumed higher amounts of foods with high nutritional density and low ED, such as fruits, vegetables and unprocessed fish, had also a lower ED than the overall population. ED was higher than the mean in the overall population for the Small-eater, Traditional and Snacker dietary patterns, patterns for which the MAR was significantly lower than the overall population.

For the ten substances considered in this study, Table 5 gives the mean exposure levels for each dietary pattern. Except for acrylamide and DON and its derivatives, the Snacker dietary pattern was significantly less exposed than the overall population for all substances studied. This result can be attributed to relatively low consumption of foods that are recognised as contributors to substance exposure. On the contrary, the Healthconscious and Mediterranean dietary patterns were more exposed than the overall population to numerous substances. For instance, these patterns showed the highest exposure level to $\mathrm{Pb}$, primarily because of higher consumption of water and hot drinks. Furthermore, as a result of their higher consumption of vegetables, individuals from the Health-conscious and Mediterranean dietary patterns were more exposed to $\mathrm{Al}$ than the overall population. The Health-conscious dietary pattern was also more exposed to PCB-NDL, primarily because of higher consumption of fish and fish products. The Basic-consumer dietary pattern was also significantly more exposed than the overall population to $\mathrm{Cd}$, because of higher consumption of bread products, and to PCB-NDL, mostly because of high consumption of butter and other dairy products. Because of their high consumption of alcohol (mainly wine), individuals belonging to the Traditional dietary pattern were more exposed to sulphites than the overall population.

\section{Discussion}

This study identified seven main dietary patterns in the adult population in France, with very distinct food consumption 
Table 3. Demographic and socio-economic determinants of each dietary pattern by sex (Odds ratios and $95 \%$ confidence intervals)

\begin{tabular}{|c|c|c|c|c|c|c|c|c|c|c|c|c|c|c|c|c|c|c|c|c|c|}
\hline & \multicolumn{3}{|c|}{ Small eater } & \multicolumn{3}{|c|}{ Health conscious } & \multicolumn{3}{|c|}{ Mediterranean } & \multicolumn{3}{|c|}{ Sweet and processed } & \multicolumn{3}{|c|}{ Traditional } & \multicolumn{3}{|c|}{ Snacker } & \multicolumn{3}{|c|}{ Basic-consumer } \\
\hline & OR & $95 \% \mathrm{Cl}$ & $P$ & OR & $95 \% \mathrm{Cl}$ & $P$ & OR & $95 \% \mathrm{Cl}$ & $P$ & OR & $95 \% \mathrm{Cl}$ & $P$ & OR & $95 \% \mathrm{Cl}$ & $P$ & OR & $95 \% \mathrm{Cl}$ & $P$ & OR & $95 \% \mathrm{Cl}$ & $P$ \\
\hline \multicolumn{22}{|l|}{ Among women } \\
\hline $\begin{array}{l}\text { Age (years) } \\
18-24\end{array}$ & 1 & & 0.211 & 1 & & $<0.001$ & 1 & & 0.002 & 1 & & $<0.001$ & 1 & & 0.328 & 1 & & $<0.001$ & 1 & & 0.105 \\
\hline $\begin{array}{l}18-24 \\
25-34\end{array}$ & $1 \cdot 21$ & $0 \cdot 66,2 \cdot 22$ & 0.540 & 2.00 & $0.46,8.70$ & 0.353 & $2 \cdot 47$ & $0.49,12.35$ & 0.272 & 1.11 & $0.58,2.14$ & 0.751 & 1.31 & $0.37,4.60$ & 0.677 & 0.60 & $0.27,1.31$ & 0.198 & 0.48 & $0.14,1.67$ & 0.251 \\
\hline $35-49$ & 1.32 & $0.74,2 \cdot 37$ & 0.346 & 4.33 & $1.02,18.40$ & 0.048 & 5.01 & $1.07,23.40$ & 0.041 & 0.60 & $0.32,1.15$ & 0.125 & 1.75 & $0.52,5.82$ & 0.365 & 0.15 & $0.06,0.39$ & 0.000 & 0.74 & $0.29,1.90$ & 0.537 \\
\hline $50-64$ & 0.81 & $0.46,1.45$ & 0.488 & 9.54 & $2.50,36 \cdot 43$ & 0.001 & 8.37 & $1.95,35.84$ & 0.004 & 0.30 & $0.14,0.65$ & 0.002 & 2.44 & $0.72,8.30$ & 0.152 & 0.03 & $0.01,0.12$ & 0.000 & 0.74 & $0.30,1.85$ & 0.526 \\
\hline 65 and + & 1.04 & $0.53,2.04$ & 0.913 & 6.49 & $1.72,24.45$ & 0.006 & 8.87 & $2.19,35.95$ & 0.002 & 0.15 & $0.05,0.44$ & 0.001 & 1.51 & $0.28,8 \cdot 27$ & 0.635 & 0.00 & $0.00,0.00$ & 0.000 & 1.47 & $0.56,3.87$ & 0.439 \\
\hline Level of education & 1 & & 0.003 & 1 & & 0.450 & & & $<0.001$ & & & 0.660 & & & $<0.001$ & & & 0.456 & & & 0.106 \\
\hline Secondary & 0.63 & $0.43,0.91$ & 0.015 & 1.18 & $0 \cdot 77,1 \cdot 82$ & 0.451 & $2 \cdot 77$ & $1 \cdot 48,5 \cdot 16$ & 0.001 & 1.14 & $0 \cdot 59,2 \cdot 18$ & 0.700 & 0.65 & $0.34,1.22$ & 0.178 & 1.04 & $0.44,2.44$ & $0.44,2.44$ & 0.87 & $0.48,1.58$ & 0.644 \\
\hline \multirow{2}{*}{$\begin{array}{l}\text { Post-secondary } \\
\text { Wealth index }\end{array}$} & 0.60 & $0.37,0.97$ & $\begin{array}{l}0.039 \\
0.368\end{array}$ & $1 \cdot 24$ & $0 \cdot 71,2 \cdot 18$ & $\begin{array}{l}0.455 \\
0.028\end{array}$ & $5 \cdot 63$ & $2 \cdot 80,11.32$ & $\begin{array}{l}0.000 \\
0.021\end{array}$ & $1 \cdot 24$ & $0.62,2.51$ & $\begin{array}{l}0.542 \\
0.196\end{array}$ & 0.22 & $0.09,0.53$ & $\begin{array}{l}0.001 \\
0.065\end{array}$ & 0.92 & $0.32,2.67$ & $\begin{array}{l}0.877 \\
0.429\end{array}$ & 0.39 & $0.18,0.87$ & $\begin{array}{l}0.021 \\
0.494\end{array}$ \\
\hline & 1 & & & 1 & & & 1 & & & 1 & & & 1 & & & 1 & & & 1 & & \\
\hline 2 & 0.77 & $0.53,1.11$ & 0.161 & 1.16 & $0.72,1.87$ & 0.544 & 1.64 & $0.88,3.08$ & 0.120 & 0.75 & $0.47,1 \cdot 19$ & 0.222 & 0.61 & $0.27,1.41$ & 0.251 & 1.46 & $0.65,3.25$ & 0.356 & 1.11 & $0.61,2.02$ & 0.721 \\
\hline \multirow{2}{*}{$\begin{array}{l}3 \\
\text { Household size }\end{array}$} & 0.71 & $0.47,1.09$ & 0.119 & $1 \cdot 70$ & $1.04,2.80$ & 0.036 & 1.73 & $0.89,3.36$ & 0.109 & 0.47 & $0.27,0.81$ & 0.007 & 0.93 & $0 \cdot 40,2 \cdot 19$ & 0.873 & 0.76 & $0.29,2.02$ & 0.582 & 1.02 & $0.47,2.20$ & 0.963 \\
\hline & 1 & & 0.060 & & & 0.052 & 1 & & 0.551 & & & 0.208 & & & 0.891 & & & 0.149 & & & 0.136 \\
\hline 3 or 4 & 0.68 & $0.42,1 \cdot 11$ & 0.122 & 0.84 & $0.46,1.53$ & 0.568 & 1.32 & $0.69,2.55$ & 0.403 & 1.03 & $0.57,1.86$ & 0.923 & 1.17 & $0.41,3.32$ & 0.775 & 2.99 & $1.42,6 \cdot 29$ & 0.004 & 0.73 & $0.30,1.74$ & 0.474 \\
\hline 5 or more & 1.08 & $0.56,2.09$ & 0.822 & 0.38 & $0.16,0.88$ & 0.024 & 1.09 & $0.43,2.75$ & 0.851 & 0.63 & $0.26,1.54$ & 0.308 & 1.26 & $0.34,4.66$ & 0.725 & 3.03 & $0.95,9.67$ & 0.061 & 1.11 & $0.35,3.46$ & 0.862 \\
\hline $\begin{array}{l}\text { Household composition } \\
\text { Single without children }\end{array}$ & & & 0.489 & & & 0.666 & & & 0.576 & & & 0.853 & & & 0.123 & & & 0.036 & & & 0.194 \\
\hline $\begin{array}{l}\text { Single without children } \\
\text { Single-parent family }\end{array}$ & $\begin{array}{l}1 \\
1.41\end{array}$ & $0.78,2.53$ & 0.257 & $1 \cdot 11$ & $0.47,2.65$ & 0.807 & $\begin{array}{l}1 \\
0.59\end{array}$ & $0.23,1.50$ & 0.269 & 0.84 & $0.40,1.77$ & 0.649 & 2.60 & $1 \cdot 11,6 \cdot 12$ & 0.029 & 0.36 & $0.13,0.98$ & 0.047 & 1.69 & $0.62,4.63$ & 0.306 \\
\hline Couple w & 1.30 & $0.89,1.88$ & 0.171 & 0.97 & $0.64,1.48$ & 0.903 & 0.77 & $0.48,1.25$ & 0.289 & 1.07 & $0.64,1.79$ & 0.789 & 2.09 & $0.90,4.84$ & 0.086 & 0.54 & $0.24,1.21$ & 0.135 & 0.75 & $0.40,1.41$ & 0.373 \\
\hline Couple with childrer & 1.44 & $0.80,2.62$ & 0.228 & 1.24 & $0.58,2.67$ & 0.576 & 0.69 & $0.28,1.73$ & 0.432 & 0.99 & $0.49,1.98$ & 0.970 & 1.27 & $0.52,3.15$ & 0.598 & 0.31 & $0.12,0.76$ & 0.011 & 1.94 & $0.55,6.82$ & 0.300 \\
\hline Occupational status & & & 0.324 & 1 & & 0.169 & 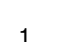 & & 0.490 & 1 & & 0.868 & & & 0.741 & & & 0.578 & & & 0.005 \\
\hline $\begin{array}{l}\text { Low } \\
\text { Medium }\end{array}$ & $\begin{array}{l}1 \\
0.73\end{array}$ & $6,1 \cdot 14$ & 0.169 & 1.08 & $0.64,1.82$ & 0.787 & 0.75 & $0.45,1.25$ & 0.272 & 1.26 & $0.73,2.18$ & 0.410 & 1.28 & $0.62,2.66$ & 0.508 & 0.94 & $0.42,2 \cdot 12$ & 0.886 & 2.61 & $1.31,5 \cdot 21$ & 0.006 \\
\hline High & 1.10 & $0.59,2.02$ & 0.768 & 1.82 & $0.90,3.68$ & 0.098 & 0.61 & $0.30,1.26$ & 0.181 & 0.87 & $0.40,1.89$ & 0.724 & 1.29 & $0.37,4.45$ & 0.690 & 1.01 & $0.37,2.77$ & 0.984 & 0.39 & $0.10,1.57$ & 0.187 \\
\hline Inactive & 0.76 & $0.53,1.11$ & 0.153 & 1.58 & $0.96,2 \cdot 60$ & 0.075 & 0.99 & $0.58,1.70$ & 0.975 & 1.01 & $0.62,1.65$ & 0.967 & 0.77 & $0.34,1.74$ & 0.526 & 0.61 & $0.31,1.22$ & 0.166 & 1.53 & $0 \cdot 87,2 \cdot 68$ & 0.143 \\
\hline Region & & & 0.059 & & & $<0.001$ & & & 0.011 & & & 0.139 & & & 0.301 & & & 0.409 & & & 0.077 \\
\hline Paris & 1 & & & 1 & & & 1 & & & 1 & & & 1 & & & 1 & & & 1 & & \\
\hline North-east & 0.77 & $0.48,1.24$ & 0.283 & 2.06 & $1.07,3.94$ & 0.030 & 0.65 & $0.33,1.27$ & 0.209 & 1.07 & $0.55,2.06$ & 0.850 & $2 \cdot 16$ & $0.70,6.65$ & 0.179 & 1.79 & $0.72,4.42$ & 0.210 & 0.52 & 0.23 & 0.120 \\
\hline North-west & 0.52 & $0.32,0.84$ & 0.007 & 3.24 & $1.68,6.25$ & 0.000 & 0.74 & $0.37,1.50$ & 0.407 & $1 \cdot 17$ & $0.60,2.29$ & 0.651 & 0.97 & $0.26,3.63$ & 0.959 & 0.94 & $0.39,2.26$ & 0.887 & 1.29 & & 0.484 \\
\hline South- $e$ & 0.85 & $0.54,1.33$ & 0.473 & 1.43 & $0.74,2.73$ & 0.284 & 1.53 & $0.85,2.77$ & 0.160 & 0.67 & $0.36,1.26$ & 0.215 & 1.39 & $0.45,4.28$ & 0.567 & $1 \cdot 16$ & $0.53,2.52$ & 0.7 & 0.65 & $0.31,1.35$ & 0.246 \\
\hline South-west & 0.64 & $0.38,1.09$ & 0.100 & 3.01 & $1.49,6.06$ & 0.002 & 1.24 & $0.61,2.51$ & 0.551 & 0.55 & $0.27,1.12$ & 0.097 & 1.51 & $0.41,5.61$ & 0.536 & 0.79 & $0.26,2 \cdot 37$ & 0.669 & 0.87 & $0.33,2.28$ & 0.772 \\
\hline Food insecurity & & & 0.009 & & & 0.026 & & & 0.016 & & & $<0.001$ & & & $<0.001$ & & & 0.004 & & & 0.081 \\
\hline $\begin{array}{l}\text { No } \\
\text { Yes }\end{array}$ & 1 & & & 1 & & & 1 & & & 1 & & & & & & 107 & & & & & \\
\hline $\begin{array}{l}\text { Yes } \\
\text { Municipa }\end{array}$ & 0.88 & $0.55,1.39$ & $\begin{array}{l}0.581 \\
0.435\end{array}$ & 1.05 & $0.60,1 \cdot 86$ & $\begin{array}{l}0.857 \\
0.873\end{array}$ & 0.72 & $0.34,1.50$ & $\begin{array}{l}0.377 \\
0.677\end{array}$ & 0.28 & $0.14,0.56$ & $\begin{array}{l}0.000 \\
0.340\end{array}$ & 1.86 & $0.86,4.03$ & $\begin{array}{l}0.115 \\
0.866\end{array}$ & 3.07 & $1 \cdot 30,7 \cdot 26$ & $\begin{array}{l}0.011 \\
0.177\end{array}$ & $1 \cdot 71$ & $0.87,3.35$ & $\begin{array}{l}0.21 \\
0.393\end{array}$ \\
\hline Rural & 1 & & & & & & 1 & & & 1 & & & 1 & & & 1 & & & 1 & & \\
\hline Small and medium & 0.78 & $0.49,1.25$ & 0.303 & 0.92 & $0.63,1.33$ & 0.656 & 1.22 & $0.68,2 \cdot 17$ & 0.503 & 0.72 & $0.40,1.29$ & 0.272 & 0.80 & $0.33,1.92$ & 0.615 & 1.74 & $0.65,4.68$ & 0.272 & 1.55 & $0.83,2.92$ & 0.171 \\
\hline Large & 0.85 & $0.62,1.16$ & 0.294 & 0.90 & $0.53,1.53$ & 0.690 & 0.93 & $0.58,1.48$ & 0.756 & 1.13 & $0.71,1.79$ & 0.607 & 0.99 & $0.51,1.91$ & 0.978 & 1.94 & $0.99,3.79$ & 0.054 & $1 \cdot 13$ & $0.68,1.88$ & 0.647 \\
\hline $\begin{array}{l}\text { Among men } \\
\text { Age (years) }\end{array}$ & & & 0.599 & & & & & & $<0.001$ & & & $<0.001$ & & & $<0.001$ & & & $<0.001$ & & & 0.064 \\
\hline $18-24$ & 1 & & 0.055 & 0.00 & $0.00,0.00$ & $<0.001$ & 1 & & $<0.001$ & 1 & & $<0.001$ & 1 & & $<0.001$ & 1 & & $<0.001$ & 1 & & 0.064 \\
\hline $25-34$ & 0.49 & $0.20,1.20$ & 0.119 & 1 & & & 4.48 & $0.43,46 \cdot 84$ & 0.210 & 0.70 & $0.30,1.66$ & 0.422 & 8.01 & $2 \cdot 40,26 \cdot 75$ & 0.001 & 0.53 & & 0.180 & $2 \cdot 65$ & 0.00 & 0.151 \\
\hline & 0.61 & $0.26,1.45$ & 0.26 & 2.35 & $0.67,8.28$ & 0.184 & 13.71 & & 0.0 & 0.37 & & 0.011 & 11.28 & 3.60 & $<0.001$ & 0.13 & & & 4.69 & 5.97 & 0.014 \\
\hline & 0.65 & $0.27,1.55$ & 0.334 & 2.72 & $0.90,8.22$ & 0.077 & 14.65 & $1.99,107.95$ & 0.009 & 0.38 & $0.16,0.89$ & 0.026 & 16.22 & $5 \cdot 34,49 \cdot 24$ & $<0.001$ & 0.01 & $0.00,0.04$ & $<0.001$ & 4.48 & $1.51,13.30$ & 0.007 \\
\hline 65 and + & 1.25 & $0.42,3.75$ & 0.691 & 2.63 & $0.71,9 \cdot 70$ & 0.148 & 15.96 & $2 \cdot 23,114 \cdot 42$ & 0.006 & 0.13 & $0.04,0.44$ & 0.001 & $16 \cdot 18$ & $4.99,52 \cdot 39$ & $<0.001$ & 0.01 & $0.00,0.05$ & $<0.001$ & 3.83 & $1.17,12.49$ & 0.026 \\
\hline $\begin{array}{l}\text { Level of education } \\
\text { Primary }\end{array}$ & & & 0.482 & & & 0.516 & & & 0.284 & & & 0.381 & & & 0.014 & & & 0.682 & & & \\
\hline $\begin{array}{l}\text { Primaary } \\
\text { Secondary }\end{array}$ & $\begin{array}{l}1 \\
0.70\end{array}$ & $0.40,1.22$ & & 0.79 & $0.37,1.67$ & & 1.38 & $0.63,3.02$ & & 1.52 & $0.71,3.25$ & & 1.21 & $0.75,1.94$ & 0.438 & 0.70 & $0.30,1.63$ & 0.407 & 0.96 & $0.49,1.89$ & 0.915 \\
\hline Post-secondary & 0.64 & $0.33,1.25$ & 0.190 & 1.00 & $0.42,2.40$ & 0.992 & 1.72 & $0.74,3.97$ & 0.204 & 1.74 & $0.71,4.26$ & 0.229 & 0.78 & $0.45,1.36$ & 0.381 & 0.79 & $0.29,2 \cdot 14$ & 0.647 & 1.33 & $0.63,2.85$ & 0.456 \\
\hline Wealth index & & & 0.918 & & & 0.027 & & & 0.608 & & & 0.901 & & & 0.814 & & & 0.033 & & & 0.624 \\
\hline 1 & 1 & & & 172 & & & 1 & & & 1 & & & 181 & & & 1 & & & 1 & & \\
\hline 2 & 0.91 & $0.53,1$ & 0.720 & 1.72 & & 0.252 & 1.90 & & 0.103 & 1.42 & & 0.303 & 0.81 & & 0.367 & 0.52 & & 0.040 & $1 \cdot 27$ & & 0.526 \\
\hline 3 & 0.98 & $0.54,1.79$ & & $2 \cdot 20$ & $0.86,5.65$ & & 1.94 & $0.83,4.55$ & 0.12 & 1.34 & $0.63,2.84$ & 0.447 & 0.72 & $0.44,1.18$ & & 0.68 & $0.32,1.45$ & & 0.95 & $0.44,2.06$ & 0.898 \\
\hline Household size & & & 0.349 & & & 0.355 & & & 0.273 & & & 0.445 & & & 0.391 & & & 0.274 & & & 0.306 \\
\hline 1 or 2 & 1 & & & 1 & & & & & & & & & & & & & & & & & \\
\hline 3 or 4 & 0.68 & $0.32,1.47$ & 0.326 & 1.43 & $0.62,3.31$ & 0.399 & 1.72 & $0.79,3.72$ & 0.169 & 0.84 & $0.43,1.62$ & 0.602 & 0.98 & & 0.938 & 1.04 & & 0.920 & 1.05 & & 0.898 \\
\hline 5 or more & 0.40 & $0.14,1.18$ & 0.098 & 0.78 & $0.19,3.23$ & 0.734 & 0.77 & $0.21,2 \cdot 86$ & 0.696 & 1.07 & $0.41,2.80$ & 0.888 & 1.31 & $0.58,2.93$ & 0.513 & 0.80 & $0.28,2 \cdot 32$ & 0.680 & 2.03 & $0.65,6.38$ & 0.225 \\
\hline
\end{tabular}




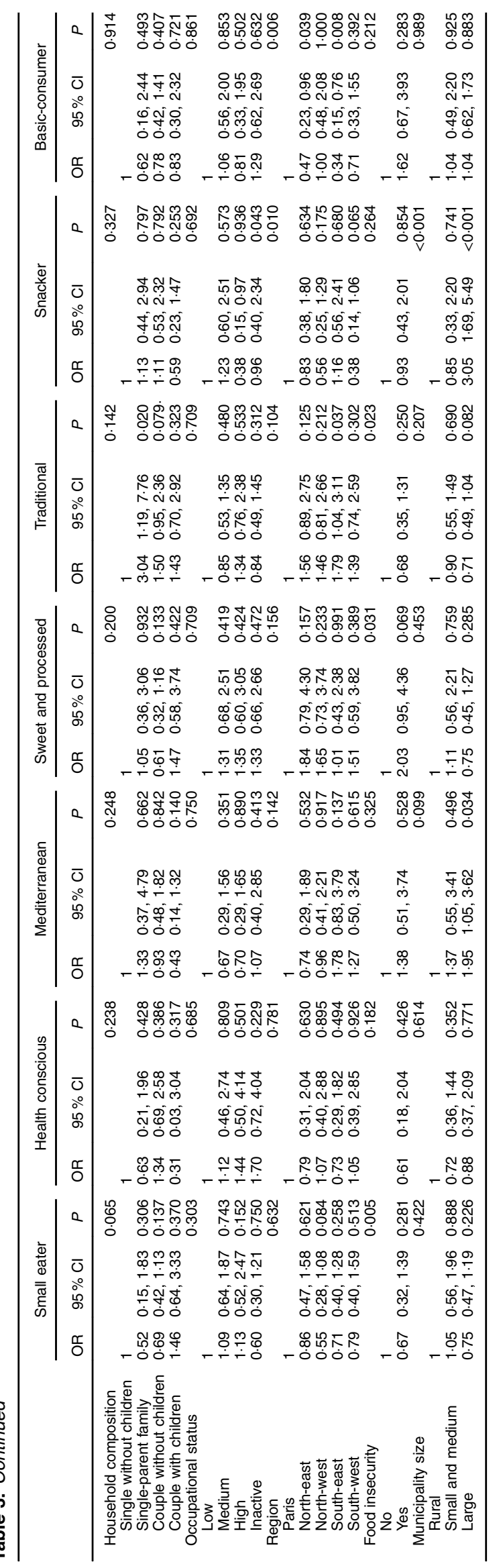

behaviours. These patterns reflected specific nutritional intake and food contaminant exposure levels, as well as particular demographic and socio-economic determinants. According to their CS composition, these patterns were named Small eater, Health conscious, Mediterranean, Sweet and processed, Traditional, Snacker and Basic consumer. The results of this study were consistent with other studies, both national and international. Indeed, the patterns reported as reproducible in the review of Newby \& Tucker ${ }^{(80)}$ (Healthy, Western, Alcohol/ Drinker, and Sweets/Dessert) are similar to some patterns we observed here. Nevertheless, although some patterns were comparable across populations (in many diverse countries and continent), there was natural variation in food consumption, which can be partly attributed to the specificity of French food culture.

First of all, two dietary patterns in particular are consistently reported in industrialised countries: one is less healthful and designated as a 'Western-style' pattern, and the other is more healthful and called the 'Prudent' pattern ${ }^{(18,24,81,82)}$. First, the Western-style pattern generally features high consumption of bread, red and processed meat, starchy foods and high-fat products and is relatively similar to the patterns described as Traditional and Basic-consumer in this study. However, some disparities remained. On one hand, the Basic-consumer pattern was also characterised by a higher consumption of basic and unprocessed foods (egg, unprocessed potatoes, pulses) than the overall population with relatively high consumption of dairy products (cream, yogurt and butter), which may specifically reflect an older French model ${ }^{(27,83)}$. On the other hand, high consumption of alcoholic drinks (in particular wine), observed in our Traditional dietary pattern, is not particularly noticed for the 'Western' diet. Other French studies have revealed an Alcohol/meat dietary pattern, but distinctive only in its amount of alcohol and meat consumed ${ }^{(28,84,85)}$. Our Traditional pattern seems to reflect at least one aspect of the French culinary culture, with its strong attachment for conviviality, and pleasure of eating ${ }^{(83,86)}$. The dietary behaviours of these two 'Western-like' dietary patterns led to less healthy nutritional intake, with high energy and SFA intake and low vitamins and minerals intake. Individuals from these patterns were likely to have a lower socio-economic status. The results tend to support the assumption, often reported in the literature, that consumption is strongly influenced by socio-economic status and notably confirm a strong relationship between a higher consumption of energy-dense foods (such as fried products, cereals, potatoes, meat and meat products) and a lower socio-economic status $^{(87-89)}$. Second, the Mediterranean and Health-conscious patterns were comparable to the 'Prudent' pattern, commonly identified in the literature. The name Mediterranean was chosen following the definition of a Mediterranean diet in the literature, such as a high consumption of whole grains and carbohydrates, fruits, vegetables, fish, olive oil, legumes and low to moderate amounts of saturated animal fats, red meat and wine ${ }^{(90,91)}$. Effectively, our Mediterranean pattern was characterised by a high consumption of fruits, vegetables, fish and oil, of which $56 \%$ was olive oil (against $52 \%$ in the overall population). Moreover, the Mediterranean Diet Score proposed by Trichopoulou et al $^{(92)}$ has been calculated for each individual and 
Table 4. Nutrient intake and diet quality indicators of each by dietary pattern (Survey-weighted mean values and standard deviations)

\begin{tabular}{|c|c|c|c|c|c|c|c|c|c|c|c|c|c|c|c|c|c|}
\hline \multirow[b]{2}{*}{ Nutrients } & \multicolumn{2}{|c|}{ Small eater } & \multicolumn{2}{|c|}{ Health conscious } & \multicolumn{2}{|c|}{ Mediterranean } & \multicolumn{2}{|c|}{ Sweet and processed } & \multicolumn{2}{|c|}{ Traditional } & \multicolumn{2}{|c|}{ Snacker } & \multicolumn{2}{|c|}{ Basic consumer } & \multicolumn{2}{|c|}{ Total pop. } & \multirow[b]{2}{*}{$P^{*}$} \\
\hline & Mean & SD & Mean & SD & Mean & SD & Mean & SD & Mean & SD & Mean & SD & Mean & SD & Mean & SD & \\
\hline Energy (kJ/d) & 6378.5 & 1771.9 & 8278.4 & 2199.5 & $8199 \cdot 8$ & $2083 \cdot 6$ & 8773.8 & $2244 \cdot 3$ & $10128 \cdot 6$ & 2431.3 & $8527 \cdot 8$ & $2599 \cdot 1$ & 9421.9 & 2771.9 & $8346 \cdot 2$ & $2576 \cdot 5$ & \\
\hline Energy (kcal/d) & $1524.5 \dagger$ & 423.5 & $1978 \cdot 6$ & $525 \cdot 7$ & $1959 \cdot 8$ & $498 \cdot 0$ & $2097.0 \ddagger$ & $536 \cdot 4$ & $2420 \cdot 8 \ddagger$ & $581 \cdot 1$ & 2038.2 & $621 \cdot 2$ & $2251.9 \ddagger$ & 662.5 & $1994 \cdot 8$ & $615 \cdot 8$ & $<0.001$ \\
\hline \multicolumn{18}{|l|}{ Macronutrients } \\
\hline Total fat $(\mathrm{g} / \mathrm{d})$ & $58 \cdot 7$ & 19.5 & $72 \cdot 2 \dagger$ & 21.5 & $80 \cdot 3 \ddagger$ & $20 \cdot 7$ & 78.7 & 23.5 & $90 \cdot 3$ & $24 \cdot 3$ & $73.6 \dagger$ & $21 \cdot 9$ & $85 \cdot 2$ & $28 \cdot 7$ & 75.5 & $25 \cdot 0$ & $<0.001$ \\
\hline SFA $(g / d)$ & $26 \cdot 3$ & 9.5 & $31.4 \dagger$ & $10 \cdot 8$ & $31.2 \dagger$ & $10 \cdot 2$ & $37.3 \ddagger$ & $12 \cdot 0$ & $41.0 \ddagger$ & $12 \cdot 5$ & $33.1 \dagger$ & $10 \cdot 6$ & $40.7 \ddagger$ & $15 \cdot 9$ & 33.7 & $12 \cdot 7$ & $<0.001$ \\
\hline Carbohydrates (g/d) & $156 \cdot 3$ & $50 \cdot 0$ & $213.5 \ddagger$ & $69 \cdot 3$ & $193.8 \dagger$ & 63.9 & $231.2 \ddagger$ & 67.5 & $220.5 \dagger$ & $72 \cdot 7$ & $224 \cdot 1 \ddagger$ & 79.4 & $243.6 \ddagger$ & 85.5 & 205.6 & 74.4 & $<0.001$ \\
\hline Simple carbo (g/d) & 64.7 & $25 \cdot 3$ & $96 \cdot 0 \ddagger$ & $32 \cdot 1$ & 89.0 & $35 \cdot 0$ & $111 \cdot 7 \ddagger$ & $38 \cdot 2$ & $78.5 \dagger$ & $35 \cdot 9$ & $99 \cdot 3 \ddagger$ & $51 \cdot 6$ & 93.9 & $40 \cdot 8$ & 87.3 & 39.5 & $<0.001$ \\
\hline Alcohol $(\mathrm{g} / \mathrm{d})$ & $6 \cdot 2$ & 8.9 & $8.6 \dagger$ & $11 \cdot 0$ & $8.6 \dagger$ & $11 \cdot 0$ & $6.0 \dagger$ & $9 \cdot 2$ & $30 \cdot 7$ & 22.8 & $7 \cdot 4$ & 13.8 & 8.6 & $11 \cdot 8$ & $11 \cdot 2$ & $16 \cdot 1$ & $<0.001$ \\
\hline Proteins (g/d) & $64.2 \dagger$ & $16 \cdot 6$ & $81.2 \ddagger$ & $19 \cdot 6$ & 79.8 & $22 \cdot 0$ & $82.0 \dagger$ & $21 \cdot 6$ & $100 \cdot 6$ & 24.9 & $80.1 \dagger$ & $25 \cdot 3$ & $90 \cdot 0$ & $26 \cdot 3$ & $81 \cdot 2$ & 24.9 & $<0.001$ \\
\hline Fibres (g/d) & $12 \cdot 3 \dagger$ & $4 \cdot 2$ & $9 \cdot 7 \ddagger$ & 6.5 & $18 \cdot 9$ & $5 \cdot 7$ & $15.8 \dagger$ & 5.5 & $16 \cdot 9 \dagger$ & $5 \cdot 8$ & $13.6 \dagger$ & 4.8 & 18.5 & $7 \cdot 2$ & $16 \cdot 1$ & $6 \cdot 2$ & $<0.001$ \\
\hline Salt $(g / d)$ & 5.4 & 1.8 & $7.2 \ddagger$ & $2 \cdot 3$ & 6.8 & $2 \cdot 3$ & $6.7 \dagger$ & $2 \cdot 1$ & 8.9 & $2 \cdot 8$ & 6.8 & $2 \cdot 6$ & 7.9 & $2 \cdot 9$ & $7 \cdot 0$ & $2 \cdot 6$ & $<0.001$ \\
\hline \multicolumn{18}{|l|}{ Minerals } \\
\hline $\mathrm{Ca}(\mathrm{mg} / \mathrm{d})$ & $668.2 \dagger$ & 235.5 & $967 \cdot 2 \ddagger$ & 297.5 & $874 \cdot 1$ & $332 \cdot 3$ & $1046 \cdot 5 \ddagger$ & 295.9 & $921.3 \dagger$ & $351 \cdot 0$ & $753.1 \dagger$ & $305 \cdot 8$ & $880 \cdot 1 \dagger$ & $307 \cdot 3$ & $856 \cdot 3$ & 326.9 & $<0.001$ \\
\hline $\mathrm{Fe}(\mathrm{mg} / \mathrm{d})$ & 9.4 & 3.7 & $12 \cdot 8$ & $5 \cdot 7$ & 12.5 & 4.7 & $13 \cdot 2 \ddagger$ & $5 \cdot 3$ & 14.9 & 4.4 & $11.2 \dagger$ & 3.9 & $12.9 \dagger$ & 4.5 & $12 \cdot 2$ & 4.9 & $<0.001$ \\
\hline $\mathrm{Na}(\mathrm{mg} / \mathrm{d})$ & $2142 \cdot 6$ & 709.8 & $2840.9 \ddagger$ & 911.8 & $2664 \cdot 6$ & 886.9 & $2653.4 \dagger$ & 818.9 & 3508.9 & $1101 \cdot 6$ & $2688.7^{\circ}$ & 1033.6 & $3098.2 \dagger$ & 1159.5 & $2750 \cdot 6$ & 1031.2 & $<0.001$ \\
\hline$M g(\mathrm{mg} / \mathrm{d})$ & $210.6 \dagger$ & 63.2 & $316.2 \ddagger$ & $121 \cdot 1$ & $281 \cdot 7 \ddagger$ & 79.6 & $281 \cdot 1$ & $75 \cdot 0$ & 313.5 & $94 \cdot 3$ & $243.7 \dagger$ & 81.0 & $288.7 \dagger$ & 85.9 & 271.2 & 93.9 & $<0.001$ \\
\hline $\mathrm{K}(\mathrm{mg} / \mathrm{d})$ & $2143 \cdot 7 \dagger$ & 548.8 & $3142 \cdot 5 \ddagger$ & 821.4 & $2986 \cdot 0 \ddagger$ & 814.1 & $2896.8 \ddagger$ & 718.5 & $3149.5 \dagger$ & 749.4 & $2356.0 \dagger$ & $721 \cdot 1$ & $3042 \cdot 8$ & 859.4 & $2760 \cdot 6$ & 837.4 & $<0.001$ \\
\hline \multicolumn{18}{|l|}{ Vitamins } \\
\hline Vit $A(\mu \mathrm{g} / \mathrm{d})$ & 910.9 & 683.3 & $1486 \cdot 8 \ddagger$ & 962.7 & $1402 \cdot 8 \ddagger$ & $1052 \cdot 0$ & $986.5 \dagger$ & 549.3 & $1447 \cdot 1$ & $1114 \cdot 6$ & $706 \cdot 2 \dagger$ & 464.3 & $1294.8 \dagger$ & 795.6 & $1160 \cdot 9$ & $882 \cdot 1$ & $<0.001$ \\
\hline Vit C $(\mu \mathrm{g} / \mathrm{d})$ & $64.2 \dagger$ & 37.3 & 116.0‡ & 52.9 & $107.5 \ddagger$ & $50 \cdot 8$ & $103.9 \ddagger$ & 54.9 & $77.8 \dagger$ & $45 \cdot 1$ & $62 \cdot 2 \dagger$ & 38.5 & $84.3 \dagger$ & 46.5 & $85 \cdot 7$ & $50 \cdot 3$ & $<0.001$ \\
\hline Vit E (mg/d) & $8 \cdot 2$ & 4.1 & $12 \cdot 1 \ddagger$ & 4.8 & $14 \cdot 1 \ddagger$ & 6.4 & $10 \cdot 4$ & 4.4 & $11.0 \dagger$ & $5 \cdot 3$ & $8.7 \dagger$ & 3.8 & $10.5 \dagger$ & $5 \cdot 0$ & $10 \cdot 5$ & $5 \cdot 2$ & $<0.001$ \\
\hline Vit $B_{1}(\mathrm{mg} / \mathrm{d})$ & $0.9 \dagger$ & 0.3 & 1.2 & 0.3 & $1 \cdot 2$ & 0.6 & $1.4 \ddagger$ & 0.5 & $1.3 \dagger$ & 0.4 & $1.1 \dagger$ & 0.4 & $1.2 \dagger$ & 0.4 & 1.2 & 0.5 & $<0.001$ \\
\hline Vit $B_{6}(m g / d)$ & $1.2 \dagger$ & 0.4 & $1 \cdot 8 \ddagger$ & 0.5 & $1.7 \ddagger$ & 0.6 & $1 \cdot 8 \ddagger$ & 0.7 & $1.8 \dagger$ & 0.5 & $1.4 \dagger$ & 0.5 & $1 \cdot 7$ & 0.6 & 1.6 & 0.6 & $<0.001$ \\
\hline Vit $B_{9}(\mu \mathrm{g} / \mathrm{d})$ & $204 \cdot 1 \dagger$ & $69 \cdot 2$ & $314.4 \ddagger$ & $87 \cdot 0$ & $309.6 \ddagger$ & $102 \cdot 9$ & $295 \cdot 2 \ddagger$ & $102 \cdot 2$ & $285 \cdot 1 \dagger$ & $90 \cdot 7$ & $208.6 \dagger$ & $76 \cdot 1$ & $277.8 \dagger$ & $86 \cdot 3$ & $265 \cdot 2$ & 97.8 & $<0.001$ \\
\hline \multicolumn{18}{|l|}{ Diet quality indicators } \\
\hline Dietary diversity score & 4.68 & 0.38 & 4.95 & 0.05 & 4.91‡ & 0.08 & 4.80 & 0.20 & 4.67† & 0.36 & $4 \cdot 27 \dagger$ & 0.83 & $4 \cdot 81$ & 0.17 & 4.81 & 0.41 & $<0.001$ \\
\hline Energy density & $1 \cdot 1 \ddagger$ & 0.7 & $0.9 \dagger$ & 0.5 & $1 \dagger$ & 0.5 & $1 \cdot 1$ & 0.7 & $1 \cdot 2 \ddagger$ & 0.7 & $1.2 \ddagger$ & 0.8 & 1 & 0.6 & $1 \cdot 1$ & 0.6 & $<0.001$ \\
\hline MAR ( $\%$ of adequacy) & $69.4 \dagger$ & $12 \cdot 9$ & $85.9 \ddagger$ & 8.6 & $84 \ddagger$ & $10 \cdot 0$ & 83.3‡ & 9.4 & $83.6 \dagger$ & 8.7 & $72.8 \dagger$ & 13.5 & 82.8 & $10 \cdot 1$ & $79 \cdot 3$ & $12 \cdot 6$ & $<0.001$ \\
\hline
\end{tabular}

Vit, vitamins; carbo, carbohydrates; pop., population; MAR, mean adequacy ratio.

*ANOVA adjusted for sex, season, level of education, wealth index, occupational status, household size, food insecurity, household composition, municipality size and region, and total energy intake (except for the variable energy), significant at $P<0.05$.

† Nutritional intake significantly lower than the overall population; significant at $P<0.05$.

₹ Nutritional intake significantly higher than the overall population. 
Table 5. Contaminant exposure levels of each dietary pattern

(Survey-weighted means and standard deviations)

\begin{tabular}{|c|c|c|c|c|c|c|c|c|c|c|c|c|c|c|c|c|c|c|c|}
\hline \multirow[b]{2}{*}{ Substance } & \multirow[b]{2}{*}{ Units } & \multirow{2}{*}{$\begin{array}{l}\text { Main contributor food } \\
\text { (\% contribution) }\end{array}$} & \multicolumn{2}{|c|}{ Small eater } & \multicolumn{2}{|c|}{ Health conscious } & \multicolumn{2}{|c|}{ Mediterranean } & \multicolumn{2}{|c|}{$\begin{array}{l}\text { Sweet and } \\
\text { processed }\end{array}$} & \multicolumn{2}{|c|}{ Traditional } & \multicolumn{2}{|c|}{ Snacker } & \multicolumn{2}{|c|}{ Basic consumer } & \multicolumn{2}{|c|}{ Total population } & \multirow[b]{2}{*}{$P^{\star}$} \\
\hline & & & Mean & SD & Mean & SD & Mean & SD & Mean & SD & Mean & SD & Mean & SD & Mean & SD & Mean & SD & \\
\hline $\mathrm{Pb}$ & $\begin{array}{l}\mu \mathrm{g} / \mathrm{kg} \text { bw } \\
\text { perd }\end{array}$ & $\begin{array}{l}\text { Alcohol }(14 \%) \text {, bread products } \\
(13 \%) \text {, water }(11 \%)\end{array}$ & 0.15 & 0.07 & $0.22 \dagger$ & 0.09 & $0.21 \dagger$ & 0.09 & $0.18 \neq$ & 0.08 & $0.22 \dagger$ & 0.08 & $0.14 \ddagger$ & 0.07 & $0.19 \ddagger$ & 0.07 & 0.18 & 0.08 & $<0.001$ \\
\hline $\mathrm{Al}$ & $\begin{array}{l}\mu \mathrm{Mg} / \mathrm{kg} \text { bw } \\
\text { per d }\end{array}$ & $\begin{array}{l}\text { Hot drinks (other than coffee) }(13 \%) \text {, } \\
\text { vegetables other than potatoes } \\
(11 \%)\end{array}$ & $30.9 \ddagger$ & 14.5 & $45 \cdot 7 \dagger$ & $20 \cdot 6$ & $42.0 \dagger$ & 18.9 & 38.1 & 14.6 & $35.0 \ddagger$ & $12 \cdot 7$ & $34 \cdot 2 \ddagger$ & $14 \cdot 3$ & 39.0 & $15 \cdot 3$ & $37 \cdot 0$ & 16.5 & $<0.001$ \\
\hline $\mathrm{Cd}$ & $\begin{array}{c}\mu \mathrm{\mu g} / \mathrm{kg} \text { bw } \\
\text { per d }\end{array}$ & Bread products $(22 \%)$ & 0.12 & 0.05 & $0.17 \dagger$ & 0.07 & 0.15 & 0.05 & $0.14 \ddagger$ & 0.05 & $0.15 \ddagger$ & 0.05 & $0.13 \ddagger$ & 0.05 & $0.17 \dagger$ & 0.06 & 0.14 & 0.06 & $<0.001$ \\
\hline Inorganic As & $\begin{array}{l}\mu \mathrm{\mu g} / \mathrm{kg} \text { bw } \\
\text { per d }\end{array}$ & $\begin{array}{l}\text { Water }(24-27 \%) \text {, coffee } \\
(14-16 \%)\end{array}$ & $0.23 \ddagger$ & 0.11 & $0.33 \dagger$ & 0.18 & 0.28 & 0.13 & 0.27 & 0.14 & 0.28 & 0.14 & $0.22 \ddagger$ & 0.13 & $0.25 \ddagger$ & 0.11 & 0.26 & 0.14 & $<0.001$ \\
\hline Organic $\mathrm{Hg}$ & $\begin{array}{l}\mu \mathrm{g} / \mathrm{kg} \text { bw } \\
\text { perd }\end{array}$ & - & 0.01 & 0.03 & 0.02 & 0.05 & $0.03 \dagger$ & 0.06 & 0.01 & 0.03 & $0.01 \ddagger$ & 0.03 & $0.01 \ddagger$ & 0.03 & 0.02 & 0.04 & 0.02 & 0.04 & $<0.001$ \\
\hline Acrylamide & $\begin{array}{l}\mathrm{ng} / \mathrm{kg} \mathrm{bw} \\
\text { perd }\end{array}$ & Fried potatoes $(45 \%)$, coffee $(30 \%)$ & 371 & 266 & 376 & 306 & $290 \ddagger$ & 228 & $389 \ddagger$ & 295 & $520 \dagger$ & 362 & $547 \dagger$ & 430 & $368 \ddagger$ & 300 & 408 & 324 & $<0.001$ \\
\hline $\begin{array}{l}\mathrm{DON} \text { and its } \\
\text { derivatives }\end{array}$ & $\mathrm{ng} / \mathrm{kg} \mathrm{bw/d}$ & Bread products $(60 \%)$ & 278 & 143 & 345 & 178 & $304 \ddagger$ & 157 & $328 \ddagger$ & 170 & $393 \ddagger$ & 195 & $377 \dagger$ & 178 & 409 & 213 & 340 & 180 & $<0.001$ \\
\hline PCB-NDL & $\begin{array}{l}\mathrm{pg} / \mathrm{kg} \text { bw } \\
\text { per d }\end{array}$ & $\begin{array}{l}\text { Fish }(37 \%) \text {, butter }(11 \%) \text {, cheese } \\
(11 \%) \text {, dairy products }(11 \%)\end{array}$ & 1501 & 1551 & $2105 \dagger$ & 2292 & 2057 & 2215 & $1555 \ddagger$ & 1234 & 1686 & 1436 & $1415 \ddagger$ & 1120 & $2010 \dagger$ & 1807 & 1728 & 1711 & $<0.001$ \\
\hline $\begin{array}{l}\text { PCDD/F and } \\
\text { PCB-DL }\end{array}$ & $\begin{array}{l}\mathrm{pg} \text { TEQ05/ } \\
\mathrm{kg} \text { bw } \\
\text { per d }\end{array}$ & Fish $(20 \%)$, butter $(20 \%)$ & 0.32 & 0.19 & 0.41 & 0.27 & 0.4 & 0.25 & $0.37 \ddagger$ & 0.18 & 0.39 & 0.2 & $0.32 \ddagger$ & 0.16 & 0.49 & 0.25 & 0.38 & 0.22 & $<0.001$ \\
\hline Sulphites & $\begin{array}{l}\mathrm{ng} / \mathrm{kg} \text { bw } \\
\mathrm{per} \mathrm{d} \\
\mu \mathrm{g} / \mathrm{kg} \\
\mathrm{bw} \text { per d }\end{array}$ & Wine $(70 \%)$ & 104 & 123 & $115 \ddagger$ & 115 & $120 \ddagger$ & 147 & $85 \ddagger$ & 117 & $334 \dagger$ & 266 & $67 \ddagger$ & 92 & $122 \ddagger$ & 133 & 141 & 180 & $<0.001$ \\
\hline
\end{tabular}

bw, Body weight; TEQ, toxicity equivalent quantity.

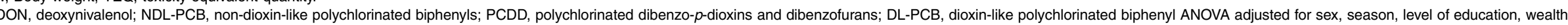
index, occupational status, household size, food insecurity, household composition, municipality size and region and total energy intake, significant at $P<0.05$.

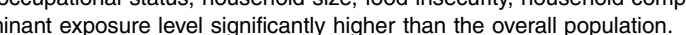

$\ddagger$ Contaminant exposure level significantly lower than the overall population; significant at $P<0.05$. 
confirmed the existence of this Mediterranean pattern among the French adult population (data not shown). Nevertheless, our Mediterranean pattern was not characterised by a high consumption of legumes and whole-grain products, as described in the literature ${ }^{(90,91)}$. Similar patterns have also been identified in other French studies ${ }^{(28,29,84)}$, but which were also characterised by high consumption of breakfast cereals, which was not observed in this study. The Health-conscious pattern describes individuals who ate more dietetic products. Few studies have identified a group of consumers characterised by high consumption of dietary products ${ }^{(93,94)}$. The consumption of diet products appeared long before the INCA2 study - that is in the $1980 \mathrm{~s}^{(95)}$; thus, the identification of such a pattern was probably because of the level of aggregation of foods chosen in this study, which identified diet products separately. Consumers in both these dietary patterns seemed to have the most nutritious dietary behaviour with a nutrient-dense diet, a higher MAR and higher consumption of foods with low ED. These dietary patterns were associated with higher socio-economic status, which support the association between a higher socio-economic status and so-called healthy foods, such as wholemeal cereal-based products, fruits and vegetables or fish already identified in the literature ${ }^{(87,88)}$.

In addition, we identified two patterns (Snacker and Sweet and processed) characterised by a high consumption of processed and modern foods (i.e. easy to prepare and to eat). Only one such pattern per study has generally been reported in the literature, either under the name of Processed/Unhealthy foods, characterised by the high consumption of high-energy beverages and savoury snacks ${ }^{(29,93)}$, or Sweets ${ }^{(96-98)}$, with a high consumption of dairy desserts and sweet products. These two profiles were both characterised by high energy intake and SFA intake. Conversely to the description of the pattern 'Sweet foods and breakfast cereal' identified by Hearty et al. ${ }^{(93)}$ among Irish adults, individuals in the Sweet-and-processed dietary pattern also had higher intake in some vitamins and minerals than the overall population, probably because of a higher consumption of fruits juices and fortified breakfast cereals. In both these dietary patterns, they were more likely to be younger, which confirms the negative association observed by Adams \& White ${ }^{(99)}$ between age and energy from ultra-processed foods (i.e. ready-to-eat, convenient and accessible foods such as breakfast cereals, biscuits, mixed dishes, pizza, etc.).

Finally, the Small-eater dietary pattern in our study was characterised by a significantly lower consumption of all foods compared with the overall population, with lower intake of micronutrients. To our knowledge, only two studies identified a similar pattern, but these studies were performed among an elderly population ${ }^{(100,101)}$. In our study, although no association was observed between this dietary pattern and age, individuals belonging to the Small-eater pattern had a tendency to be older (11, 17, 32, 21 and 19\% of individuals from the Small-eater pattern were 18-24, 25-34, 34-49, 50-64 and >64 years old, respectively; data not shown). Because the presence of underreporters might have suggested potential bias, their distribution was studied. In fact, under-reporters did not represent the majority of individuals from this pattern ( $48 \%$ of individuals from the Small-eater pattern were identified as under-reporters), and, consequently, those individuals who had lower energy intake than the overall population could be considered as real small consumers.

As reported in other studies, dietary patterns can highlight the specific food habits, preferences and availability of the countries $^{(80,102)}$. The multiplicity of dietary patterns identified in this work clearly reflects the contradictory attitudes of the French population toward food, such as health awareness, indulgence, pleasure, conviviality, but also convenience and practicality ${ }^{(103,104)}$. These different food consumption behaviours were also noticeable in the BMI, as defined by the World Health Organization $^{(5)}$. For instance, profiles with 'healthy' food behaviour (i.e. the Health-conscious and Mediterranean patterns) had a lower proportion of individuals considered as overweight (32.8 and $29.1 \%$, respectively) or obese (13.0 and $10.9 \%)$ than the more 'unhealthy' profiles, such as the Traditional pattern ( $44 \%$ of overweight and $15.5 \%$ of obese individuals).

One original aspect of our work was to focus, in addition to the nutritional quality of the diet, on food contaminant exposure levels of each dietary pattern. Whereas Health-conscious and Mediterranean dietary patterns seemed to have healthy dietary behaviours, these two groups of consumers seemed to be more at risk for exposure to some chemical substances. In comparison with health-based guidance values $(\mathrm{HBGV})^{(51)}$, the Healthconscious pattern was considered to be at risk for its exposure to $\mathrm{Pb}, \mathrm{Cd}$, inorganic $\mathrm{As}$ and $\mathrm{Al}$, and the Mediterranean pattern was identified to be at risk for its exposure to $\mathrm{Pb}$, inorganic As, organic Hg and NDL-PCB. Conversely, the Snacker pattern had a higher ED, a lower MAR and, in comparison with recommended nutrient intake values, the highest prevalence of inadequate nutrient intake (data not shown). However, according to the HBGV, its exposure to the ten substances studied was not considered to match at-risk levels (except for acrylamide exposure). Finally, our results suggest that diets should be analysed further according to a risk:benefit ratio. Unfortunately, no comparison can be made here because, to our knowledge, to date, no other study in the literature has characterised the dietary patterns by levels of contaminant exposure.

Otherwise, this study shows that the novel factorial analysis used, the NMF, was well adapted to determining dietary patterns and successfully summarised the precise variability of food consumption in a given population. Moreover, by using an appropriate algorithm, this is the first study on this topic for which individual sampling weight was taken into account in the NMF to be representative of the French adult population ${ }^{(23,34)}$. In contrast to PCA, for which dietary patterns are constructed based on an opposition of 'foods consumed' and 'non-consumed', the NMF constructs food behaviour patterns using only a positive association of foods, which may better reflect reality. In addition, although it is well known that food consumption is a multidimensional phenomenon, classical factorial analysis approaches mean that one dietary pattern corresponds to one common underlying dimension (factor) of food consumption $^{(18,28)}$. With NMF, one dietary pattern can be represented by different CS. Thus, as an example, consumers from the Traditional dietary pattern were characterised by foods 
composing the Traditional CS (processed meat, alcoholic drinks, coffee, etc.) but also the High-fat/sugar/salt CS (grains and nuts, crackers, etc.). Moreover, our study used different levels of aggregation of foods and distinguished some dietary patterns that were previously confounded in other studies and provided a better characterisation of those patterns. For instance, Bertin et al. ${ }^{(29)}$ identified five dietary patterns named Traditional, Diversified, Processed, Prudent and Sandwiches using a PCA based on the average frequency of consumption of forty-three food groups from the INCA2 survey. According to the foods that characterised the dietary patterns, the Processed pattern was similar to the Snacker and Sweet-and-processed patterns of this study, and the Prudent pattern was similar to the Health-conscious and Mediterranean dietary patterns. Furthermore, the Processed pattern identified by Bertin et al. ${ }^{(29)}$ differed from the overall population only by the higher consumption of sandwiches and lower consumption of other foods, whereas our Snacker dietary pattern included individuals who consumed higher quantities of several foods (sandwiches, pizza, sodas and colas, processed potato products, etc.) than the overall population. These differences further demonstrate that the NMF provides a better characterisation of the different food consumption behaviours.

Another major strength of this study was that it was based on two robust national studies. First, the INCA2 survey was conducted on a large and representative sample of the French adult population using a complex sampling frame design, with a robust collection of dietary intake using a 7-d food record, as well as numerous variables relative to demographic and socio-economic status ${ }^{(37)}$. For the TDS2 study, a complex food sampling plan covering $90 \%$ of the French diet was designed, taking into account the seasonal nature of products and the regional variations, leading to an accurate assessment of the population exposure at the national level ${ }^{(50)}$. In addition, the use of factorial analysis raises some concerns about the degree of subjectivity involved in the analytical process (e.g. the determination of the number of CS, the level of aggregation of foods, the determination of the number of patterns identified). However, as highlighted in Newby \& Tucker ${ }^{(80)}$, the consistency and reproducibility with regard to other national and international studies help to confirm the validity of our findings.

In conclusion, from the INCA2 survey, we identified seven distinct dietary patterns in the French adult population, with specific demographic, socio-economic, nutritional and environmental characteristics. These findings provide new information on the diversity of food consumption in France and give an overview of the nutritional quality of the different food consumption behaviours. From a public health perspective, our results provide interesting insights for developing behaviourally targeted policies. In addition, because of contradictory results for a given dietary pattern between high-quality nutritional intake and high contaminant exposure levels (and vice versa), this study also demonstrates the necessity to analyse the risks and the benefits of food consumption behaviours, particularly in a public health context. Finally, the food consumption data were collected several years ago (i.e. 2006-2007) and the third INCA survey is currently underway, potentially providing the opportunity to assess the trends in dietary patterns at the national level.

\section{Acknowledgements}

The authors wish to thank the CIQUAL for providing the national food composition tables, the Institut de Sondage Lavialle (ISL) team for the collection of data, and all the families for their cooperation.

This research received institutional support from the French agency for food, environmental and occupational health safety (ANSES).

R. G. designed the study, analysed and interpreted the data, wrote the manuscript and had primary responsibility for final content. C. B. and S. H. contributed to the analytical approach, the interpretation of the results and revised each draft. S. H., P. D.-P., C. D., V. S. and A. C. contributed to the design of the surveys (INCA2 and EAT2), to the data collection and help to write the paper.

The authors have no financial or personal conflicts of interest to declare.

\section{Supplementary material}

For supplementary material/s referred to in this article, please visit http://dx.doi.org/10.1017/S0007114516001549

\section{References}

1. Willett WC \& Stampfer MJ (2013) Current evidence on healthy eating. Annu Rev Public Health 34, 77-95.

2. Martinez-Gonzalez MA \& Bes-Rastrollo M (2014) Dietary patterns, Mediterranean diet, and cardiovascular disease. Curr Opin Lipidol 25, 20-26.

3. de la Fuente-Arrillaga C, Martinez-Gonzalez M, Zazpe I, et al. (2014) Glycemic load, glycemic index, bread and incidence of overweight/obesity in a Mediterranean cohort: the SUN project. BMC Public Health 14, 1091.

4. He J (1999) Dietary sodium intake and subsequent risk of cardiovascular disease in overweight adults. JAMA 282, 2027.

5. World Health Organization (2015) Obesity and overweight. WHO. http://www.who.int/mediacentre/factsheets/fs311/en/ (accessed March 2015).

6. Reddy KS \& Katan MB (2004) Diet nutrition and the prevention of hypertension and cardiovascular diseases. Public Health Nutr 7, 167-186.

7. Sayon-Orea C, Bes-Rastrollo M, Gea A, et al. (2014) Reported fried food consumption and the incidence of hypertension in a Mediterranean cohort: the SUN (Seguimiento Universidad de Navarra) project. Br J Nutr 112, 984-991.

8. McCartney DMA, Byrne DG \& Turner MJ (2015) Dietary contributors to hypertension in adults reviewed. Ir J Med Sci 184, 81-90.

9. de Oliveira Otto MC, Mozaffarian D, Kromhout D, et al. (2012) Dietary intake of saturated fat by food source and incident cardiovascular disease: the Multi-Ethnic Study of Atherosclerosis. Am J Clin Nutr 96, 397-404.

10. Lee D-H, Folsom AR \& Jacobs DR (2005) Iron, zinc, and alcohol consumption and mortality from cardiovascular diseases: the Iowa Women's Health Study. Am J Clin Nutr 81, 787-791.

11. Mente A, de Koning L, Shannon HS, et al. (2009) A systematic review of the evidence supporting a causal link between dietary factors and coronary heart disease. Arch Intern Med 169, 659. 
12. Liu J \& Ma DWL (2014) The role of $n$-3 polyunsaturated fatty acids in the prevention and treatment of breast cancer. Nutrients 6, 5184-5223.

13. Wang Q, Hao J, Guan Q, et al. (2014) The Mediterranean diet and gastrointestinal cancers risk. Recent Pat Food Nutr Agric 6, 23-26.

14. Glade MJ (1999) Food, nutrition, and the prevention of cancer: a global perspective. American Institute for Cancer Research/World Cancer Research Fund, American Institute for Cancer Research, 1997. Nutrition 15, 523-526.

15. Jacobs DR \& Tapsell LC (2007) Food, not nutrients, is the fundamental unit in nutrition. Nutr Rev 65, 439-450.

16. Gerber M (2001) The comprehensive approach to diet: a critical review. J Nutr 131, 3051S-3055S

17. Jacobs DR \& Steffen LM (2003) Nutrients, foods, and dietary patterns as exposures in research: a framework for food synergy. Am J Clin Nutr 78, 508S-513S.

18. Hu FB (2002) Dietary pattern analysis: a new direction in nutritional epidemiology. Curr Opin Lipidol 13, 3-9.

19. Michels KB \& Schulze MB (2005) Can dietary patterns help us detect diet-disease associations? Nutr Res Rev 18, 241.

20. Moeller SM, Reedy J, Millen AE, et al. (2007) Dietary patterns: challenges and opportunities in dietary patterns research. J Am Diet Assoc 107, 1233-1239.

21. Nutrition Evidence Library (2014) A Series of Systematic Reviews on the Relationship Between Dietary Patterns and Health Outcomes. Alexandria, VA: Department of Agriculture, Center for Nutrition Policy and Promotion.

22. Tucker KL (2010) Dietary patterns, approaches, and multicultural perspective. This is one of a selection of papers published in the CSCN-CSNS 2009 Conference, entitled Can we identify culture-specific healthful dietary patterns among diverse populations undergoing nutrition transition? Appl Physiol Nutr Metab 35, 211-218.

23. Béchaux C, Zetlaoui M, Tressou J, et al. (2013) Identification of pesticide mixtures and connection between combined exposure and diet. Food Chem Toxicol 59, 191-198.

24. Kant AK (2004) Dietary patterns and health outcomes. $J$ Am Diet Assoc 104, 615-635.

25. Schulze MB \& Hoffmann K (2006) Methodological approaches to study dietary patterns in relation to risk of coronary heart disease and stroke. Br J Nutr 95, 860-869.

26. Wirfält E, Drake I \& Wallström P (2013) What do review papers conclude about food and dietary patterns? Food Nutr Res 57, 10.3402/fnr.v57i0.20523.

27. Mahe T, Francou A, Colin J, et al. (2011) Comparaison des modèles alimentaires Français et Etat-uniens (Comparison of French and American Diet Models). Crédoc. Cahier de Recherche no. 283. Paris: Crédoc.

28. Kesse-Guyot E, Bertrais S, Péneau S, et al. (2009) Dietary patterns and their sociodemographic and behavioural correlates in French middle-aged adults from the SU.VI. MAX cohort. Eur J Clin Nutr 63, 521-528.

29. Bertin M, Touvier M, Dubuisson C, et al. (2015) Dietary patterns of French adults: associations with demographic, socio-economic and behavioural factors. J Hum Nutr Diet 29, 241-254.

30. Escalon H, Bossard C \& Beck F (2009) Typologie des mangeurs (Typology of eaters). In Baromètre Santé Nutrition 2008 (Health and Nutrition Barometer 2008), pp. 305-325 [H Escalon, C Bossard and F Beck, editors]. Saint-Denis: INPES.

31. Kipnis V, Midthune D, Buckman DW, et al. (2009) Modeling data with excess zeros and measurement error: application to evaluating relationships between episodically consumed foods and health outcomes. Biometrics 65, 1003-1010.
32. Shlens J (2014) A tutorial on principal component analysis. Int J Remote Sensing 51, 1-12.

33. Lee DD \& Seung HS (1999) Learning the parts of objects by non-negative matrix factorization. Nature $\mathbf{4 0 1}$, 788-791.

34. Zetlaoui M, Feinberg M, Verger P, et al. (2011) Extraction of food consumption systems by nonnegative matrix factorization (NMF) for the assessment of food choices. Biometrics 67, 1647-1658.

35. Sy MM, Feinberg M, Verger P, et al. (2013) New approach for the assessment of cluster diets. Food Chem Toxicol 52, 180-187.

36. Agence française de sécurité sanitaire, alimentation, environnement, travail (ANSES) (2009) INCA2 (2006-2007). Report of the Individual and the National Study on Food Consumption no. 199. Maisons-Alfort: French Food Safety Agency (AFSSA).

37. Dubuisson C, Lioret S, Touvier M, et al. (2010) Trends in food and nutritional intakes of French adults from 1999 to 2007: results from the INCA surveys. Br J Nutr 103, 1035-1048

38. Lioret S, Touvier M, Dubuisson C, et al. (2009) Trends in child overweight rates and energy intake in france from 1999 to 2007: relationships with socioeconomic status. Obesity 17, 1092-1100.

39. French National Institute of Statistics and of Economic Studies (INSEE) (2007) Enquête emploi de 2005 (Employment Survey 2005). Insee Résultats 68, 1-4.

40. European Food Safety Authority (2009) General principles for the collection of national food consumption data in the view of a pan-European dietary survey. EFSA J 7, 51 .

41. Lioret S, Dubuisson C, Touvier M, et al. (2010) Trends in food and nutritional intakes of French adults from 1999 to 2007: results from the INCA surveys. Br J Nutr $\mathbf{1 0 3}$, $1035-1048$

42. Hercberg S, Deheeger M \& Preziosi P (editors) (1994) Portions alimentaires: manuel-photos pour l'estimation des quantités (Portion Sizes: Picture Booklet for the Estimation of Quantities). Paris: Polytechnica.

43. McCann SE, Marshall JR, Brasure JR, et al. (2001) Analysis of patterns of food intake in nutritional epidemiology: food classification in principal components analysis and the subsequent impact on estimates for endometrial cancer. Public Health Nutr 4, 989-997.

44. Bailey RL, Gutschall MD, Mitchell DC, et al. (2006) Comparative strategies for using cluster analysis to assess dietary patterns. J Am Diet Assoc 106, 1194-1200.

45. Grieger JA, Scott J \& Cobiac L (2011) Dietary patterns and breast-feeding in Australian children. Public Health Nutr 14, 1939-1947.

46. Fillol F, Dubuisson C, Lafay L, et al. (2011) Accounting for the multidimensional nature of the relationship between adult obesity and socio-economic status: the French second National Individual Survey on Food Consumption (INCA 2) dietary survey (2006-2007). Br J Nutr 106, 1602-1608.

47. Darmon N, Bocquier A, Vieux F, et al. (2009) L'insécurité alimentaire pour raisons financières en France (Food insecurity for financial reasons in France). In Trav. L'Observatoire Natl. Pauvr. L'Exclusion Soc., pp. 583-602 [La documentation Française, editor]. Yvry: INRA.

48. Feinberg M, Favier J-C \& Laussucq C (1995) Répertoire général des aliments (General Inventory of Foods). Paris: Institut national de la recherche agronomique: Technique \& Documentation - Lavoisier. 
49. Ireland J, du Chaffaut L, Oseredczuk M, et al. (2008) French Food Composition Table, version 2008.1. French Food Safety Agency (Afssa). http://www.afssa.fr/TableCIQUAL/ index.html (accessed February 2014).

50. Sirot V, Volatier JL, Calamassi-Tran G, et al. (2009) Core food of the French food supply: second Total Diet Study. Food Addit Contam Part Chem Anal Control Expo Risk Assess 26, 623-639.

51. French Agency for Food, Environmental and Occupational Health \& Safety (ANSES) (2011) Second French Total Diet Study, TDS 2. Report 1-Inorganic Contaminants, Minerals, Persistent Organic Pollutants, Mycotoxins and Phytoestrogens. Maisons-Alfort: ANSES.

52. French Agency for Food, Environmental and Occupational Health \& Safety (ANSES) (2011) Second French Total Diet Study, TDS 2. Report 2 - Pesticide Residues, Additives, Acrylamide and Polycyclic Aromatic Hydrocarbons. Maisons-Alfort: ANSES.

53. Wang G, Kossenkov AV \& Ochs MF (2006) LS-NMF: a modified non-negative matrix factorization algorithm utilizing uncertainty estimates. BMC Bioinformatics 7, 175-185.

54. Kaufman L (2005) Finding Groups in Data: An Introduction to Cluster Analysis. Hoboken, NJ: Wiley.

55. Lê S, Josse J \& Husson F (2008) FactoMineR: an R package for multivariate analysis. J Stat Softw 25, 1-18.

56. Lebart L, Morineau A \& Piron M (1997) Statistique Exploratoire Multidimensionnelle (Multidimensional and Exploratory Statistics), 2nd ed., pp. 1-480. Paris: Dunod.

57. Novaković R, Cavelaars A, Geelen A, et al. (2014) Review article socio-economic determinants of micronutrient intake and status in Europe: a systematic review. Public Health Nutr 17, 1031-1045.

58. Bocquier A, Vieux F, Lioret S, et al. (2015) Socio-economic characteristics, living conditions and diet quality are associated with food insecurity in France. Public Health Nutr 7, 1-10.

59. Hanna KL \& Collins PF (2015) Relationship between living alone and food and nutrient intake. Nutr Rev 73, 594-611.

60. Wang Y-M, Mo B-Q, Takezaki T, et al. (2003) Geographical variation in nutrient intake between urban and rural areas of Jiangsu province, China and development of a semiquantitative food frequency questionnaire for middle-aged inhabitants. J Epidemiol 13, 80-89.

61. Cappuccio FP, Ji C, Donfrancesco C, et al. (2015) Geographic and socioeconomic variation of sodium and potassium intake in Italy: results from the MINISAL-GIRCSI programme. BMJ Open 5, e007467.

62. Wirt A \& Collins CE (2009) Diet quality - what is it and does it matter? Public Health Nutr 12, 2473.

63. Alkerwi A (2014) Diet quality concept. Nutrition 30 , 613-618

64. Kant AK \& Graubard BI (2005) Energy density of diets reported by American adults: association with food group intake, nutrient intake, and body weight. Int $J$ Obes $\mathbf{2 9}$, 950-956.

65. Vieux F, Soler L-G, Touazi D, et al. (2013) High nutritional quality is not associated with low greenhouse gas emissions in self-selected diets of French adults. Am J Clin Nutr 97, 569-583.

66. Kant AK (1996) Indexes of overall diet quality: a review. J Am Diet Assoc 96, 785-791.

67. Ledikwe JH, Blanck HM, Khan LK, et al. (2006) Low-energydensity diets are associated with high diet quality in adults in the United States. J Am Diet Assoc 106, 1172-1180.

68. American Institute for Cancer Research \& World Cancer Research Fund (2007) Food, Nutrition, Physical Activity and the Prevention of Cancer: A Global Perspective: A Project of World Cancer Research Fund International. Washington, DC: American Institute for Cancer Research.

69. Swinburn BA, Caterson I, Seidell JC, et al. (2004) Diet, nutrition and the prevention of excess weight gain and obesity. Public Health Nutr 7, 123-146.

70. Keller HH, Ostbye T \& Bright-See E (1997) Predictors of dietary intake in Ontario seniors. Can J Public Health 88, 305-309.

71. Krebs-Smith SM, Smiciklas-Wright H, Guthrie HA, et al. (1987) The effects of variety in food choices on dietary quality. J Am Diet Assoc 87, 897-903.

72. Maillot M, Darmon N, Vieux F, et al. (2007) Low energy density and high nutritional quality are each associated with higher diet costs in French adults. Am J Clin Nutr 86, 690-696.

73. Torheim LE, Ouattara F, Diarra MM, et al. (2004) Nutrient adequacy and dietary diversity in rural Mali: association and determinants. Eur J Clin Nutr 58, 594-604.

74. Ruel MT (2003) Operationalizing dietary diversity: a review of measurement issues and research priorities. J Nutr $\mathbf{1 3 3}$, 3911S-3926S.

75. Lucenteforte E, Garavello W, Bosetti C, et al. (2008) Diet diversity and the risk of squamous cell esophageal cancer. Int J Cancer 123, 2397-2400.

76. Garavello W, Giordano L, Bosetti C, et al. (2008) Diet diversity and the risk of oral and pharyngeal cancer. Eur J Nutr 47, 280-284.

77. Drewnowski A, Henderson SA, Shore A, et al. (1996) Diet quality and dietary diversity in France implications for the French paradox. J Am Diet Assoc 96, 663-669.

78. Gaujoux R \& Seoighe C (2010) A flexible R package for nonnegative matrix factorization. BMC Bioinformatics 11, 367.

79. Lumley T (2015) Analysis of complex survey samples. J Stat Softw 9, 1-19.

80. Newby PK \& Tucker KL (2004) Empirically derived eating patterns using factor or cluster analysis: a review. Nutr Rev 62, 177-203.

81. Wu K (2006) Dietary patterns and risk of prostate cancer in US men. Cancer Epidemiol Biomarkers Prev 15, $167-171$.

82. Sofianou A, Fung TT \& Tucker KL (2011) Differences in diet pattern adherence by nativity and duration of US residence in the Mexican-American population. J Am Diet Assoc 111, 1563-1569.e2

83. Mahe T, Tavoularis G \& Pilorin T (2009) La Gastronomie s'inscrit dans la continuité du modèle alimentaire Français. Crédoc. Cahier de Recherche no. 267. Paris: Crédoc.

84. Charreire H, Kesse-Guyot E, Bertrais S, et al. (2011) Associations between dietary patterns, physical activity (leisure-time and occupational) and television viewing in middle-aged French adults. Br J Nutr 105, 902-910.

85. Bessaoud F, Tretarre B, Daurès J-P, et al. (2012) Identification of dietary patterns using two statistical approaches and their association with breast cancer risk: a case-control study in southern France. Ann Epidemiol 22, 499-510.

86. Poulain J-P (2001) Manger aujourd'hui attitudes, normes et pratiques (Eat Today: Norms, Attitudes, Usages). Toulouse: Privat.

87. Darmon N \& Drewnowski A (2008) Does social class predict diet quality? Am J Clin Nutr 87, 1107-1117.

88. Vlismas K \& Stavrinos V (2009) Socio-economic status, dietary habits and health-related outcomes in various parts of the world: a review. Cent Eur J Public Health 17, 55-63.

89. Trichopoulou A, Naska A \& Costacou T (2002) Disparities in food habits across Europe. Proc Nutr Soc 61, 553-558. 
90. Sofi F (2009) The Mediterranean diet revisited: evidence of its effectiveness grows. Curr Opin Cardiol 24, 442-446.

91. Georgoulis M, Kontogianni M \& Yiannakouris N (2014) Mediterranean Diet and diabetes: prevention and treatment. Nutrients 6, 1406-1423.

92. Trichopoulou A, Costacou T, Bamia C, et al. (2003) Adherence to a Mediterranean diet and survival in a Greek population. N Engl J Med 348, 2599-2608.

93. Hearty ÁP \& Gibney MJ (2009) Comparison of cluster and principal component analysis techniques to derive dietary patterns in Irish adults. Br J Nutr 101, 590.

94. Ax E, Warensjö Lemming E, Becker W, et al. (2016) Dietary patterns in Swedish adults; results from a national dietary survey. Br J Nutr 115, 95-104.

95. Institut national de prévention et d'éducation pour la santé (France) (2008) Baromètre santé environnement 2007 (Health, Nutrition and Environment Barometer 2007). Saint-Denis: Éd. INPES.

96. Venkaiah K, Brahman GNV \& Vijayaraghavan K (2011) Application of factor analysis to identify dietary patterns and use of factor scores to study their relationship with nutritional status of adult rural populations. J Health Popul Nutr 29, 327-338.

97. Lin H, Bermudez OI \& Tucker KL (2003) Dietary patterns of Hispanic elders are associated with acculturation and obesity. J Nutr 133, 3651-3657.
98. Newby PK, Muller D, Hallfrisch J, et al. (2004) Food patterns measured by factor analysis and anthropometric changes in adults. Am J Clin Nutr 80, 504-513.

99. Adams J \& White M (2015) Characterisation of UK diets according to degree of food processing and associations with socio-demographics and obesity: cross-sectional analysis of UK National Diet and Nutrition Survey (2008-2012). Int J Behav Nutr Phys Act 12, 160-172.

100. Corrêa Leite ML, Nicolosi A, Cristina S, et al. (2003) Dietary and nutritional patterns in an elderly rural population in Northern and Southern Italy: (I). A cluster analysis of food consumption. Eur J Clin Nutr 57, 1514-1521.

101. Schroll K, Carbajal A, Decarli B, et al. (1996) Food patterns of elderly Europeans. SENECA investigators. Eur J Clin Nutr 50 , Suppl. 2, S86-S100.

102. Engeset D, Hofoss D, Nilsson LM, et al. (2015) Dietary patterns and whole grain cereals in the Scandinavian countries - differences and similarities. The HELGA project. Public Health Nutr 18, 905-915.

103. Laisney C (2011) L'évolution de l'alimentation en France. Panorama des tendances lourdes (Evolution of the diet in France. Overview of the major trends). Futuribles 371, 1-8.

104. Laisney C (2011) L'évolution de l'alimentation en France. Tendances émergentes et ruptures possibles (Evolution of the diet in France. Emerging trends and possible breakdowns). Futuribles 372, 1-4. 